\title{
Comparison of Different Numerical Models of RC Elements for Predicting the Seismic Performance of Structures
}

\author{
Abdelhakim Zendaoui $^{1 \text { ), }}$, A. Kadid ${ }^{1)}$, and D. Yahiaoui ${ }^{2)}$ \\ (Received February 9, 2016, Accepted September 9, 2016, Published online September 27, 2016)
}

\begin{abstract}
This paper aims to provide guidelines for the numerical modeling of reinforced concrete (RC) frame elements in order to assess the seismic performance of structures. Several types of numerical models RC frame elements are available in nonlinear structural analysis packages. Since these numerical models are formulated based on different assumption and theories, the models accuracy, computing time, and applicability vary, which poses a great difficulty to practicing engineering and limits their confidence in the analysis resultants. In this study, the applicability of four representative numerical models of RC frame elements is evaluated through comparison with experimental results of four-storey bare frame available from European Laboratory for Structural Assessment. The accuracy of a numerical model is evaluated according to the top displacement, interstorey drift, Maximum storey shear, damage pattern and energy dissipation capacity of the frame structure. The results obtained allow a better understanding of the characteristics and potentialities of all procedures, helping the user to choose the best approach to perform nonlinear analysis.
\end{abstract}

Keywords: nonlinear numerical model, RC frame elements, seismic analysis, force-based, displacement-based, plastic hinge, fiber element.

\section{Introduction}

The advent of performance-based earthquake engineering has placed an emphasis on simulating the nonlinear response of a structural system to seismic excitations (Filippou and Fenves 2004). Nonlinear frame analysis techniques are seeking practical design applications in assessing the performance of building structures and bridges under static and dynamic loads. New performance-based seismic design guidelines FEMA-273 (1997) require that buildings be analyzed using nonlinear static pushover analyses or nonlinear dynamic analyses to control the global and local demands. The use of nonlinear frame analysis necessitates the availability of robust and computationally efficient models for performing analyses in a reasonable amount of time (Coleman and Spacone 2001).

The dynamic analysis of reinforced concrete (RC) buildings under earthquake loading is generally carried out with beam-column elements, which should be able to duly take into account the inelastic behavior of the actual member

\footnotetext{
${ }^{1)}$ Department of Civil Engineering, University of Batna 2, Batna 05000, Algeria.

*Corresponding Author;

E-mail: zendaoui-abdelhakim@hotmail.fr

${ }^{2)}$ Department of Civil Engineering, University of Frères Mentouri, Constantine 25000, Algeria.

Copyright $($ The Author(s) 2016. This article is published with open access at Springerlink.com
}

(Almeida et al. 2012). Accurate and computationally efficient numerical models that represent the cyclic loading of plastic hinges in beam-column elements, including the effect of degradation, are thus required to simulate the seismic response and evaluate the performance of structural systems (Scott and Fenves 2006).

Several studies have investigated the performance of different nonlinear modeling strategies to simulate the response of RC columns subjected to dynamic loads. Hashemi et al. (2012) studied the nonlinear response of reinforced concrete moment-resisting frames considering the bond slip effect between concrete and bars along the lengths of beam, column and joint elements. They used fiber model theory to simulate the behavior of reinforced concrete in the nonlinear domain, but the perfect bond assumption between the concrete and bars was removed. The comparison between numerical model and experimental of two specimens under cyclic loading showed that the proposed method can model the nonlinear behavior of reinforced concrete frames with very good precision.

Ladjinovi et al. (2012) carried out a comparative study concerning structural models for seismic analysis of multistorey frame buildings using SAP2000 and OpenSees. SAP2000 and OpenSees programmers offer more opportunities for the selection of material models, elements and solution algorithms for nonlinear analysis, depending on the type of material, designing of structural elements, cross section and type of analysis. The results of the nonlinear static pushover analysis, obtained using SAP2000 and OpenSees, were satisfactory from the point of view of 
character changes in the force-displacement relationship. Moreover, Huang et al. (2015) made a comparison between numerical models for RC frame elements available in nonlinear structural analysis packages (Opensees, VecTor2, VecTor5, Response-2000) and experimental test results for 232 rectangular and 88 circular RC cantilever columns are available in the PEER column database to evaluate the accuracy of the numerical models the global response of the element. Each element is based on different assumption and theories [MCFT-based continuum element (VT2-MCFT), MCFT-based frame element (VT5-MCFT), Element with plastic hinge integration method (OS-PHIM), Force-based beam-column element (OS-FBBC) and Section-analysis based element $(\mathrm{R} 2 \mathrm{~K})]$. In order to reach this objective, three accuracy measures were used; energy dissipation capacity, peak strengths, and initial stiffness. The hysteretic behavior of an RC element is largely influenced by failure modes, the previous accuracy measures are evaluated against the shear force demand-capacity ratio $\left(I_{v}\right)$. If an element is flexurecritical $\left(I_{v}<0.5\right)$, then all tested models accurately predicted the peak strengths and energy dissipation capacities. The accuracy increased as $I_{v}$ decreased. If an element is shearcritical, $\left(I_{v}>1\right)$, then VT2-MCFT and VT5-MCFT most accurately predicted the specimens' hysteretic behavior. OSFBBC and OS-PHIM could not capture peak strengths and hysteretic behavior (energy dissipation capacity) because of the inherent assumptions in their numerical model formulation. The implication of these modeling assumptions on dynamic response highly depends on the structural period. The parametric study shows that for a relatively long-period structure ( $\mathrm{T}=1.0 \mathrm{~s}$ or greater), accurately capturing the failure mode and hysteretic behavior does not influence the global response of the structure. For a short-period shearcritical structure, the global response can be largely different depending on the adopted numerical model.

Rodrigues et al. (2012) made a comparison between lumped plasticity and distributed inelasticity. The results of experimental and numerically analysis of 24 columns show that the global envelope response is satisfactorily represented with the three modeling strategies, but significant differences were found in the strength degradation for higher drift demands and energy dissipation. Furthermore, Mazza et al. (2010) proposed a lumped plasticity model for the nonlinear static and dynamic analyses of three dimensional reinforced concrete, a bilinear moment-curvature law and an interaction surface axial force-biaxial bending moment are considered. The nonlinear dynamic analysis is performed using a two-parameter implicit integration scheme and an initial-stress like iterative strategy, adopting the Haar-Karman principal. After a numerical investigation, the LPM is reliable and relatively simple, so it can be efficiently used for the nonlinear dynamic analysis of complex multi-storey RC framed structures.

This study addresses the influence of different simplifications, assumptions and uncertainties in modeling reinforced concrete (RC) frame elements on the seismic performance of structures. Emphasis is made on the applicability of four representative numerical models of RC frame elements, which is evaluated through comparison with experimental results for four-storey bare frame available from European Laboratory for Structural Assessment (ELSA) (Pinto et al. 2002), that can be readily performed with existing software packages. The structural response is assessed by nonlinear dynamic (time history) analysis, to estimate the seismic response.

\section{Numerical Tool and Modeling Strategies}

The numerical analyses developed and described in this paper with different nonlinear modeling strategies were studied using the computer program SeismoStruct v7 (SeismoSoft and 2015). The program includes models for the representation of the behavior of spatial frames under static and/or dynamic loading, considering both material and geometric nonlinearities. With this software, seven types of analyses can be performed, namely: dynamic and static timehistory analysis, conventional and adaptive pushover, incremental dynamic analysis, modal analysis, and static analysis (possibly nonlinear) under quasi-permanent loading. The software allows the use of elements with distributed inelasticity and elements with lumped-plasticity, all the elements are based on force or displacement formulations. While the evaluated numerical models are based on different assumptions, input parameters for these elements are primarily physical properties such as section geometry and uniaxial behavior of materials. Hence, as long as the limitation of the element can be clearly defined, which is the objective of this research, practicing engineering can use the elements without much effort to calibrate model parameters.

Therefore, in this study, four nonlinear modeling strategies. The first one is force based and the plasticity is distributed along the entire length of the structural member (inelastic force-based frame element -distributed plasticity) IFBEDP. The second model is a distributed inelasticity forced-based element where the inelasticity is spread within a fixed length of the element, as proposed by Scott and Fenves (2006) (inelastic force-based frame element - plastic hinge length) IFBEPHL. The third model is formulated in terms of displacements and the plasticity is distributed along the length of element (inelastic displacement-based frame element-distributed plasticity) IDBEDP, and the fourth is a displacement based element with plasticity concentrated at the two element's ends (Giberson 1967, 1969) (inelastic displacement-based frame element - concentrated plasticity) IDBECP (Fig. 1). The four modeling strategies were applied to each column and beam and the obtained results were compared with experimental results to evaluate the accuracy of each numerical model.

\section{Element Formulations}

\subsection{Stiffness (Displacement) Method}

In the stiffness method the displacement fields of the element are discretized and interpolated in terms of $n_{d o f}$ generalized displacement degrees of freedom $\mathbf{q}$ such that 


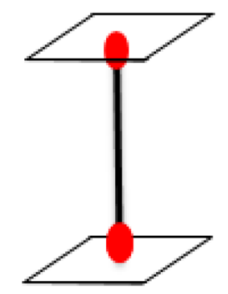

(a)

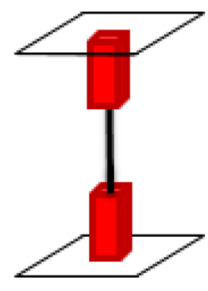

(b)

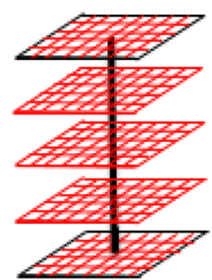

(c)
Fig. 1 Idealized Models of Beam-Column Elements: a Plastic hinge concentrated at the two element's ends, b distributed plasticity on a specific length, but concentrated at the ends of the element, c distributed plasticity with fiber section approach.

$$
\mathbf{u}(x)=\mathrm{N}(x) \mathbf{q}
$$

where

$$
\mathrm{N}(x)=\left[\begin{array}{ccc}
N_{u}(x) & 0 & 0 \\
0 & N_{w}(x) & 0 \\
0 & 0 & N_{v}(x)
\end{array}\right]
$$

Is a $3 \times n_{\text {dof }}$ matrix containing the vectors of interpolation functions $N_{u}, N_{w}$, and $N_{v}$ for the three displacement fields $u$, $w$, and $v$, respectively. The expression for the deformation fields $\mathbf{d}(x)$ is then

$$
\mathbf{d}(x)=\mathbf{B}(x) \mathbf{q}
$$

where the strain-displacement transformation matrix $\mathbf{B}$ contains first and second derivatives of the displacement shape functions according to the kinematic relationships. Replacing $\boldsymbol{\Delta d}$ from the incremental version of Eq. (3) in the constitutive relation $\mathbf{\Delta D}=\mathbf{k} \mathbf{\Delta} \mathbf{d}$, yields the relation

$$
\Delta \mathbf{D}(x)=\mathbf{k}(x) \Delta \mathbf{d}(x)=\mathbf{k}(x) \mathbf{B}(x) \Delta \mathbf{q}
$$

For the force field increment $\Delta \mathbf{D}(x)$. The principle of virtual displacements leads to the equilibrium condition

$$
\mathbf{Q}=\int_{0}^{L} \mathbf{B}^{T}(x) \mathbf{D}(x) d x
$$

And its linearization

$$
\mathbf{k} \Delta \mathbf{q}=\mathbf{R}
$$

In the form of a force-displacement relation, where $\mathbf{Q}=$ element resisting forces and

$$
\mathbf{K}=\frac{\partial \mathbf{Q}}{\partial \mathbf{q}}=\int_{0}^{L} \mathbf{B}^{T}(x) \mathbf{k}(x) \mathbf{B}(x) d x
$$

Represents the element stiffness matrix, while $\Delta \mathbf{q}$ and $\mathbf{R}$ are vectors of displacement increments and residual forces, respectively; and $L$ denotes the elements length (Limkatanyu and Spacone 2002).

\subsection{Flexibility (Force) Method}

In the flexibility method the force fields are described by the relation

$$
\mathbf{D}(x)=\mathbf{b}(x) \mathbf{Q}
$$

Where $\mathbf{b}(x)$ contains the force interpolation functions, which relate the generalized nodal forces $\mathbf{Q}$ to the internal forces $\mathbf{D}(x)$. Replacing $\Delta \mathbf{D}$ from the incremental version of Eq. (8) in the inverse from the constitutive relation $\Delta \mathbf{D}=\mathbf{k} \Delta \mathbf{d}$, namely $\quad \Delta \mathbf{d}(x)=\mathbf{k}^{-\mathbf{1}} \boldsymbol{\Delta} \mathbf{D}(x)$, yields the incremental deformation field (Limkatanyu and Spacone 2002).

$$
\Delta \mathbf{d}(x)=\mathbf{f}(x) \Delta \mathbf{D}(x)=\mathbf{f}(x) \mathbf{b}(x) \Delta \mathbf{Q}
$$

where $\mathbf{f}(x)=\mathbf{k}^{-\mathbf{1}}(x)=$ section flexibility matrix. The principle of virtual forces leads of the compatibility condition

$$
\mathbf{q}=\int_{0}^{L} \mathbf{b}^{T}(x) \mathbf{d}(x) d x
$$

and its linearization

$$
\mathbf{F} \Delta \mathbf{Q}=\mathbf{r}
$$

In the form of a displacement-force relation, where $\mathbf{q}=$ element end displacement; and

$$
F=\frac{\partial \mathbf{q}}{\partial \mathbf{Q}}=\int_{0}^{L} \mathbf{b}^{T}(x) \mathbf{f}(x) \mathbf{b}(x) d x
$$

Is the element flexibility matrix, while $\Delta \mathbf{Q}$ and $\mathbf{r}$ are vectors of force increments and residual displacement, respectively. Note that a meaningful expression for the flexibility matrix $\mathbf{F}$ can only be derived for the beam element without rigid-body modes (Scott et al. 2004).

\section{Plasticity Models}

\subsection{Distributed Plasticity Model}

In this approach, the entire member is modeled as an inelastic element, the source of such inelasticity being defined at the sectional level. The global inelasticity of the frame is obtained by integration of the contribution provided by each controlling section (Fig. 2). A major advantage of such models is the nonexistence of a predetermined length where the inelasticity can occur, because all the sections can have excursions in this field of response. Though this approach is a closer approximation to reality, it also requires more computational capacity; that is, more analysis time, as well as memory and disk space (Calabrese et al. 2010).

\subsection{Lumped Plasticity Model}

The plastic hinge length, $l_{p}$, of RC members depends on a number of parameters, including the definition of yielding and ultimate curvatures, section geometry, material properties, compression and tension reinforcement, transverse reinforcement, cracking and tension-stiffening, the stressstrain curve for the concrete in tension and compression (Roh et al. 2012). 


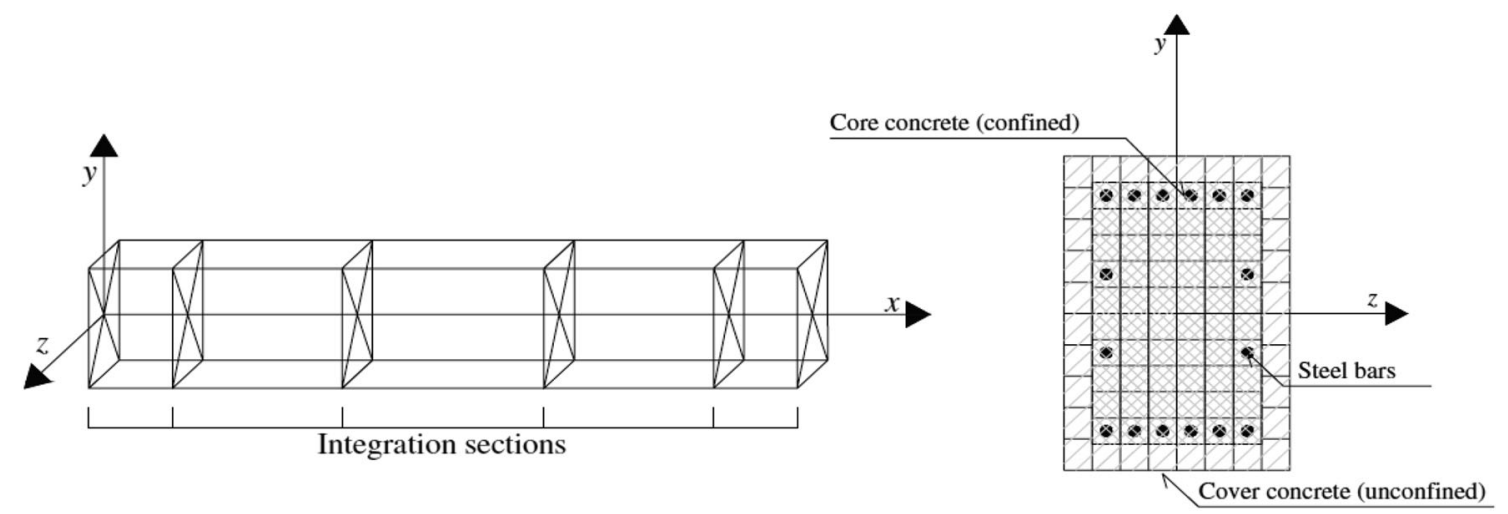

Fig. 2 Example of controlling sections along the element and $\mathbf{b}$ section fiber discretization.

General expressions for the plastic hinge length, $l_{p}$. Some popular expressions for the calculation of plastic hinge length are presented in Table 1.

\section{Engineering Limit States}

Within the context of performance-based engineering, it is paramount that analysts and engineers are capable of identifying the instants at which different performance limit states (e.g. non-structural damage, structural damage, and collapse) are reached. The sequence of damage was similar for all elements of structure. The most notable observations, in sequence of first occurrence, were concrete cracking, longitudinal reinforcement yielding, initial spalling of the concrete cover, complete spalling of the concrete cover, spiral fracture, longitudinal reinforcement buckling, and longitudinal reinforcement fracture. And so on. It requires significant modeling efforts and computing time to model all these features. It is recognized that the plastic rotation, drift ratio and displacement ductility levels are associated with specific damage categories may vary considerably with the structural system and construction material.

Therefore, the concept of plastic rotation is considered in this study, for identification the limit states.

The real moment-rotation curve of a RC member in which the tension steel yields, can be idealised to a simplified bilinear curve, as shown in Fig. 3 for a typical RC beam (Park and Paulay 1975). In Fig. 3, point B corresponds to the tensile yield strain in the steel indicating yield moment, $M_{y}$, and yield rotation, $\theta_{y}$, while point $\mathrm{C}$ corresponds to the ultimate conditions; namely ultimate moment, $M_{u}$, and

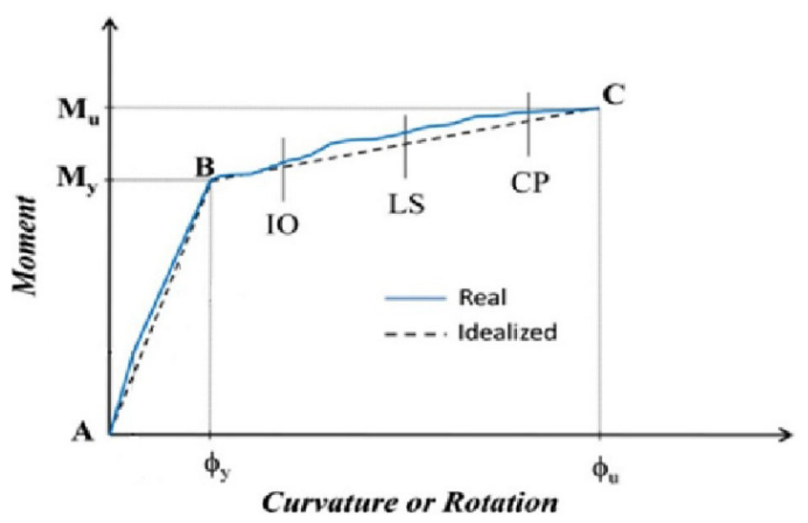

Fig. 3 A typical real moment-rotation (or moment-curvature) and the corresponding idealised curve for a flexural plastic hinge.

corresponding ultimate rotation, $\theta_{u}$. The ultimate condition was considered to be the attainment of one of the following conditions; whichever happened first (Park and Paulay 1975; Ramin and Fereidoonfar 2015).

1. A $20 \%$ drop in the moment capacity of member.

2. When the tensile strain in the longitudinal steel reaches the ultimate tensile strain.

3. The attainment of the ultimate compression strain in concrete using the following equation proposed by Scott et al. (Scott et al. 1982).

Although not the main focus of this study, the acceptance criteria of immediate occupancy (IO), life safety (LS) and collapse prevention (CP) were defined for the beam and columns similar to the ratios recommended in FEMA-356 (1997).

Table 1 Expressions for the calculation of plastic hinge length $\left(l_{p}\right)$.

\begin{tabular}{c|c|c}
\hline Authors & Year & \multicolumn{1}{c}{$l_{p}$} \\
\hline \hline Priestley and Park (1987) & 1987 & $l p=0.08 L+6 d_{b}(13)$ \\
\hline Paulay and Priestley (1992) & 1992 & $l p=0.08 L+0.022 f_{y} d_{b}(14)$ \\
\hline Panagiotakos and Fardis (2001) & 2001 & $l p=0.12 L+0.014 . a_{s 1} f_{y} d_{b}(15)$ \\
\hline Berry et al. (2008) & 2008 & $l p=0.05 L+0.1 \frac{f_{y} d_{b}}{\sqrt{f_{c}^{\prime}}(16)}$ \\
\hline
\end{tabular}




\section{Bar buckling}

It is expected that during strong earthquakes, longitudinal reinforcing steel in reinforced concrete structural elements may undergo large tension and compression strain reversals. Because of insufficient tie spacing, this repeated loading into the inelastic range may lead to buckling of steel reinforcing bars (Rodriguez et al. 1999). The onset of buckling of longitudinal bars in reinforced concrete columns is a key damage state (Fig. 4) because unlike less severe levels of flexural damage, bar buckling requires extensive repairs (Lehman et al. 2001), significantly reduces the structure's functionality (Eberhard 2000), and has clear implications for structural safety.

Berry et al. (2005) presented the following Eq. (9) for calculating the plastic rotation:

$$
\begin{aligned}
\theta_{b b}= & C_{0}\left(1+C_{1} \rho_{e f f}\right)\left(1+C_{2} \frac{P}{A_{g} f_{c}^{\prime}}\right)^{-1} \\
& \left(1+C_{3} \frac{L}{D}+C_{4} \frac{f_{y} d_{b}}{D}\right)
\end{aligned}
$$

The five constants in Eq. (17) $\left(C_{0}, \ldots, C_{4}\right)$ are presented in Table $2, \rho_{\text {eff }}$ is the effective confinement ratio, $\mathrm{L}$ is the length of the column, $\mathrm{D}$ is the column depth, $A_{g}$ is the gross area of column cross section, $d_{b}$ is the bar diameter of longitudinal reinforcement, and $f_{c}^{\prime}$ is the compressive strength of concrete.

\section{Structure, Materials and Loads}

In the present study, the modeling of a full-scale, fourstorey with three bays, 2D bare frame as is shown in Fig. 5. The reinforced concrete frame tested at the European Laboratory for Structural Assessment (ELSA) (Pinto et al. 2002) under two subsequent pseudo-dynamic loadings, first using

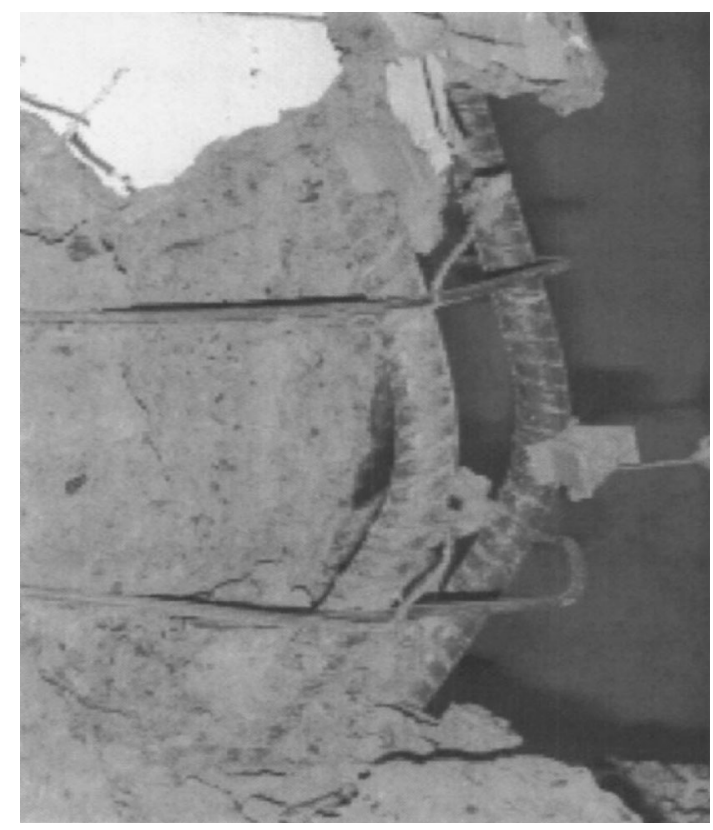

Fig. 4 Typical buckling of longitudinal bar in a spiralreinforced column. the Acc-475 input motion and then the Acc-975 input motion. It can be considered representative of design and construction common in Southern European countries such as Italy, Portugal and Greece in the 1950's and 1960's for the assessment, Strengthening and Repair aims at a key contribution for the calibration and subsequent adoption of the codes in Europe. It was designed for vertical loads only.

From the numerical analyses of this frame, it was observed that it has a resistance to horizontal loads, in terms of ultimate limit state, of approximately $8 \%$ of their weight. Similar analysis, in terms of allowable stresses, as was common practice at the time, would lead to lateral resistance of $5 \%$ of the frame weight (Carvalho et al. 1999). In addition, all elements used in this study are only inelastic flexural failure mode, However, some past studies (Inel and Ozmen 2006; Jeong and Elnashai 2005) have reported that even for under-designed RC buildings, possessing inadequate transverse reinforcement, the shear demand is significantly lower than the shear capacity in both beams and columns and that no shear failure would occur. The shear force demand-capacity ratio is defined as

$$
I_{v}=\frac{M}{V L}
$$

where $M$ is the maximum flexural strength, $L$ is the length of the cantilever column, and $\mathrm{V}$ is the shear force capacity. Thus, an $I_{v}$ value of greater than 1 implies that the column will reach shear force capacity before it reaches maximum moment capacity, that is, shear failure. If the $I_{v}$ value is less than 1 , then the column is expected to develop flexural failure. Both the flexural capacity, M, and shear capacity, V, are calculated based on the approach proposed by Priestley et al. (Priestley et al. 1994) is invoked, which has been developed for both circular and rectangular columns. According to this approach, $\mathrm{V}$ is given by

$$
V=k \sqrt{f_{c}}\left(0.80 A_{g}\right)+N \tan \alpha+\frac{A_{w} f_{y w}\left(d-d^{\prime}\right) \cdot \cot \theta}{s}
$$

where $k$ is a parameter depending on the curvature ductility demand as shown in Fig. 6, and $\alpha$ is the angle between the column axis and the line joining the centers of the flexural compression zones at the top and bottom of the column. For the initial shear primary curve, $V_{u o}$ is derived by setting in Eq. (19) the value of $k$ corresponding to the curvature ductility demand $\mu_{\varphi} \leq 3$ (i.e.no strength degradation).

The $I_{v}$ values of structure columns are shown in Table 3, where in all cases, the $I_{v}$ values are less than 1, so the columns are expected to develop flexural failure.

\subsection{Structural Geometry}

A typical two-way slab system was adopted, with $5 \mathrm{~m}$ transverse spans, $150 \mathrm{~mm}$ thick slabs and $500 \mathrm{~mm}$ deep beams throughout the building. The columns have the characteristics indicated in Fig. 7 where it is noticeable that only column 2 is working in its stronger axis, as a result of the non-seismic design philosophy adopted. Consequently, this member plays a dominant role in the response of the frame and is here after referred to as "strong" column. The 
Table 2 Results of regression analyses.

\begin{tabular}{c|c|c|c|c|c|c}
\hline \multirow{2}{*}{$\begin{array}{c}\text { Column } \\
\text { deformation }\end{array}$} & Column type & \multicolumn{5}{|c}{ Coefficients } \\
\cline { 2 - 7 } & & $C_{0}$ & $C_{1}$ & $C_{2}$ & $C_{3}$ & $C_{4}$ \\
\hline \hline$\theta_{b b}(17)$ & $\begin{array}{c}\text { Rectangular- } \\
\text { reinforced }\end{array}$ & 0.019 & 1.650 & 1.797 & 0.012 & 0.072 \\
\cline { 2 - 7 } & Spiral-reinforced & 0.006 & 7.190 & 3.129 & 0.651 & 0.227 \\
\hline
\end{tabular}
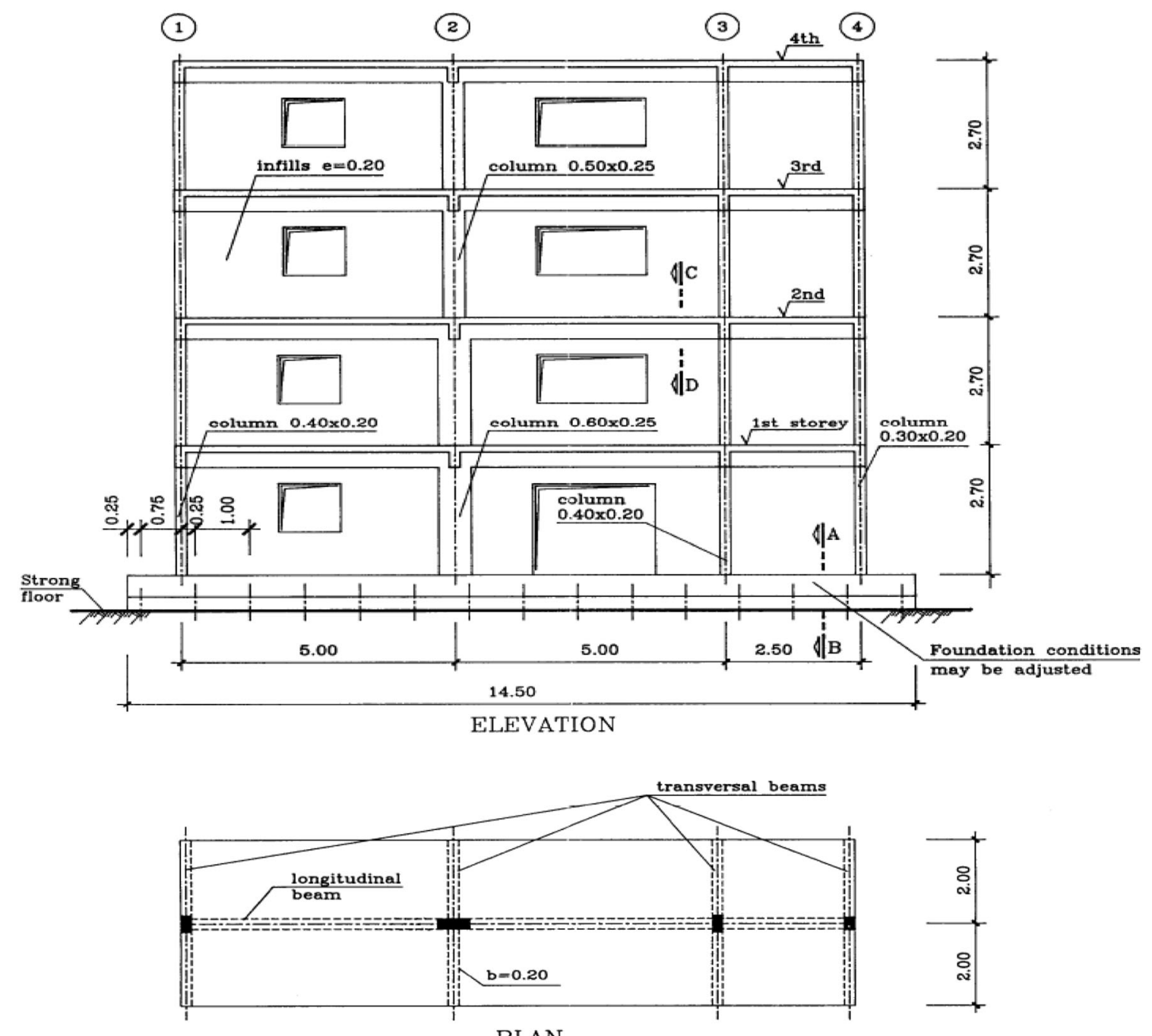

Fig. 5 Four-storey, three-bay RC frame geometry (m), (elevation and plan views, after Carvalho et al. 1999).

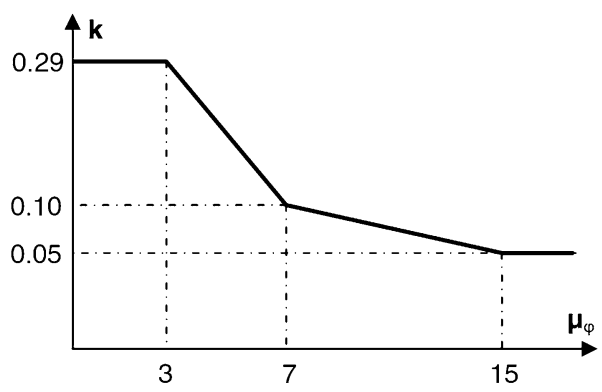

Fig. 6 Relationship between curvature ductility demand and strength of concrete shear resisting mechanisms (Priestley et al. 1994). lap splice detailing, partially shown in Fig. 4, also strongly influences the response of the structure since it increases further the strength differential between the second and third stories. Further detailing of beams, slab and foundation can be found in Carvalho et al. (1999).

\subsection{Loading}

The vertical loads considered in the design consisted of the self-weight of the slab and transverse beams, finishes, infill walls and the quasi-permanent static load. The Fig. 8 shows the scheme of vertical loads applied to the structure.

The input seismic motions were defined in order to be representative of a moderate-high European seismic hazard scenario. Hazard consistent time series of acceleration (15 s 
Table 3 Results of The shear force demand-capacity ratio $\left(I_{\mathrm{V}}\right)$.

\begin{tabular}{c|c|c|c|c}
\hline Section $(\mathrm{b} \times \mathrm{h})$ & V total $(\mathrm{KN})$ & VxL $(\mathrm{KN} \times \mathrm{m})$ & $\mathrm{M}(\mathrm{KN} \times \mathrm{m})$ & $\mathrm{Iv}$ \\
\hline \hline $250 \times 600$ & 213.0536589 & 287.622439 & 247.27 & 0.85970344 \\
\hline $400 \times 200$ & 64.76455409 & 87.432148 & 36.43 & 0.41666596 \\
\hline $300 \times 200$ & 53.68678094 & 72.4771543 & 26.9 & 0.37115144 \\
\hline $250 \times 500$ & 143.7311598 & 194.037066 & 113.9 & 0.58700125 \\
\hline
\end{tabular}

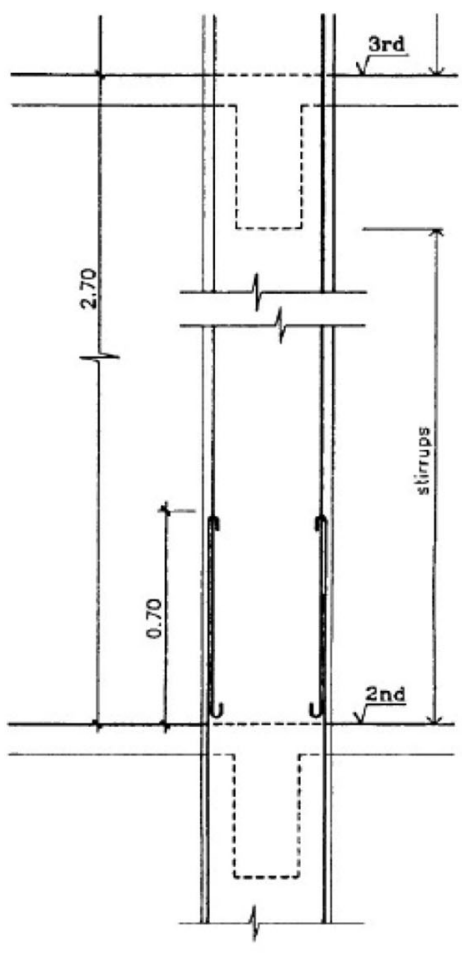

(a)

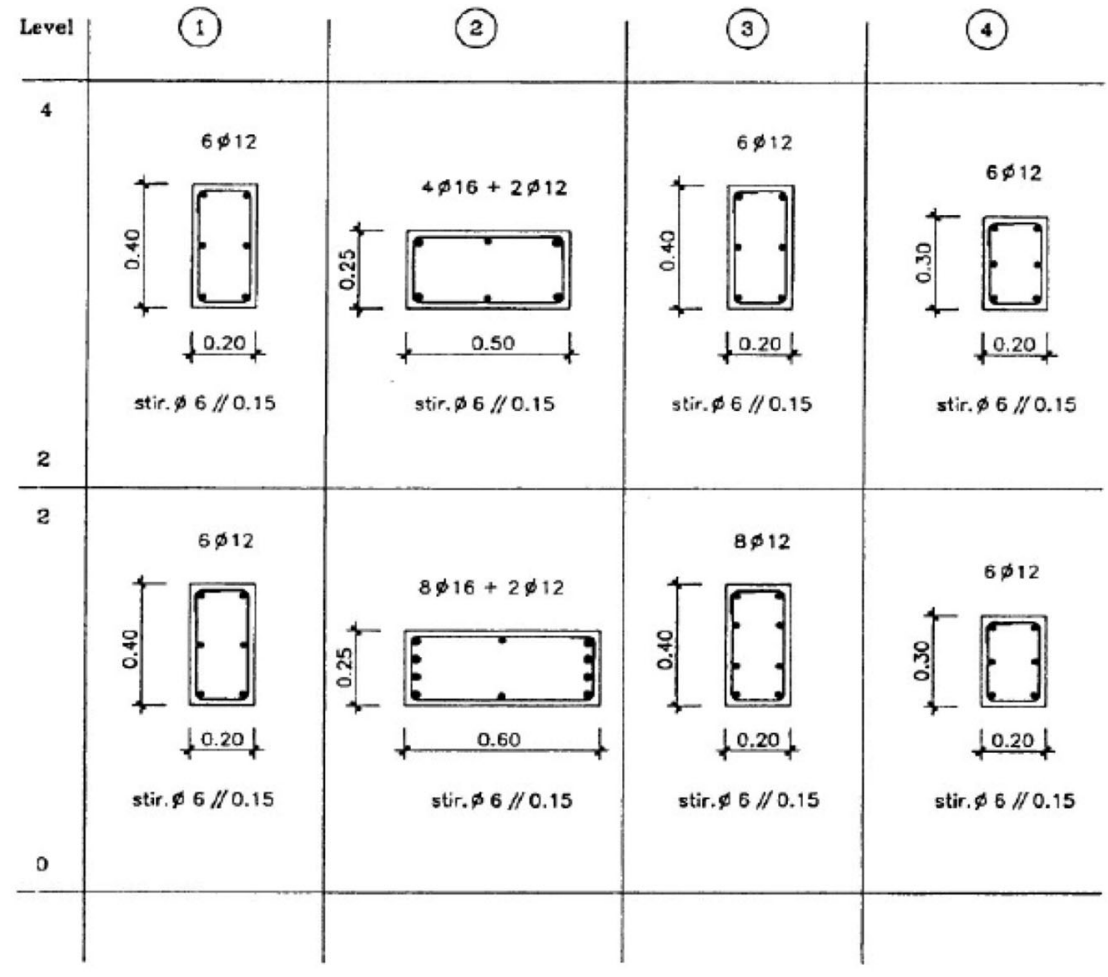

(b)

Fig. 7 Four-storey, three-bay RC frame geometry (m), (reinforcement details of the columns, after Carvalho et al. 1999).

duration) were artificially generated (Figs. 9, 10), and two with different return periods were chosen: 475 years (peak acceleration $2.180 \mathrm{~m} / \mathrm{s}^{2}$ ) BF475 and 975 years (peak acceleration $2.884 \mathrm{~m} / \mathrm{s}^{2}$ ) BF975 (ELSA) (Pinto et al. 2002).

\subsection{Material Properties \\ 6.3.1 Concrete Model}

Mander et al. (1988) have proposed a unified stress-strain approach for confined concrete applicable to both circular and rectangular shaped transverse reinforcement. The stressstrain model is illustrated in Fig. 11 and $f_{c c}^{\prime}$ is based on an equation suggested by Popovics (1973). For a slow (quasistatic) strain rate and monotonic loading, the longitudinal compressive concrete stress is given by:

$$
f=\frac{f_{c c}^{\prime} x r}{r-1+x^{r}}
$$

where $f_{c c}^{\prime}$ is the compressive strength of confined concrete and $x$ is a ratio of longitudinal compressive concrete strain $\left(\varepsilon_{c}\right), r$ is the ratio of the concrete's initial modulus to the difference of the initial and secant moduli of elasticity. These parameters and their components are mathematically expressed by:

$$
\begin{aligned}
& x=\frac{\varepsilon_{c}}{\varepsilon_{c c}} \\
& \varepsilon_{c c}=\varepsilon_{c o}\left[1+5\left(\frac{f_{c c}^{\prime}}{f_{c o}^{\prime}}-1\right)\right]
\end{aligned}
$$

As suggested by Richart et al. (1928), where $f_{c c}^{\prime}$ and $\varepsilon_{c o}=$ the unconfined concrete strength and corresponding strain, respectively (generally $\varepsilon_{c o}=0.002$ can be assumed), and

$$
r=\frac{E_{c}}{E_{c}-E_{\text {sec }}}
$$

where

$$
E_{c}=5000 \sqrt{f_{c o}^{\prime}} \mathrm{MPa}
$$

Is the tangent modulus of elasticity of the concrete (1 $\mathrm{MPa}=145 \mathrm{psi})$, and 


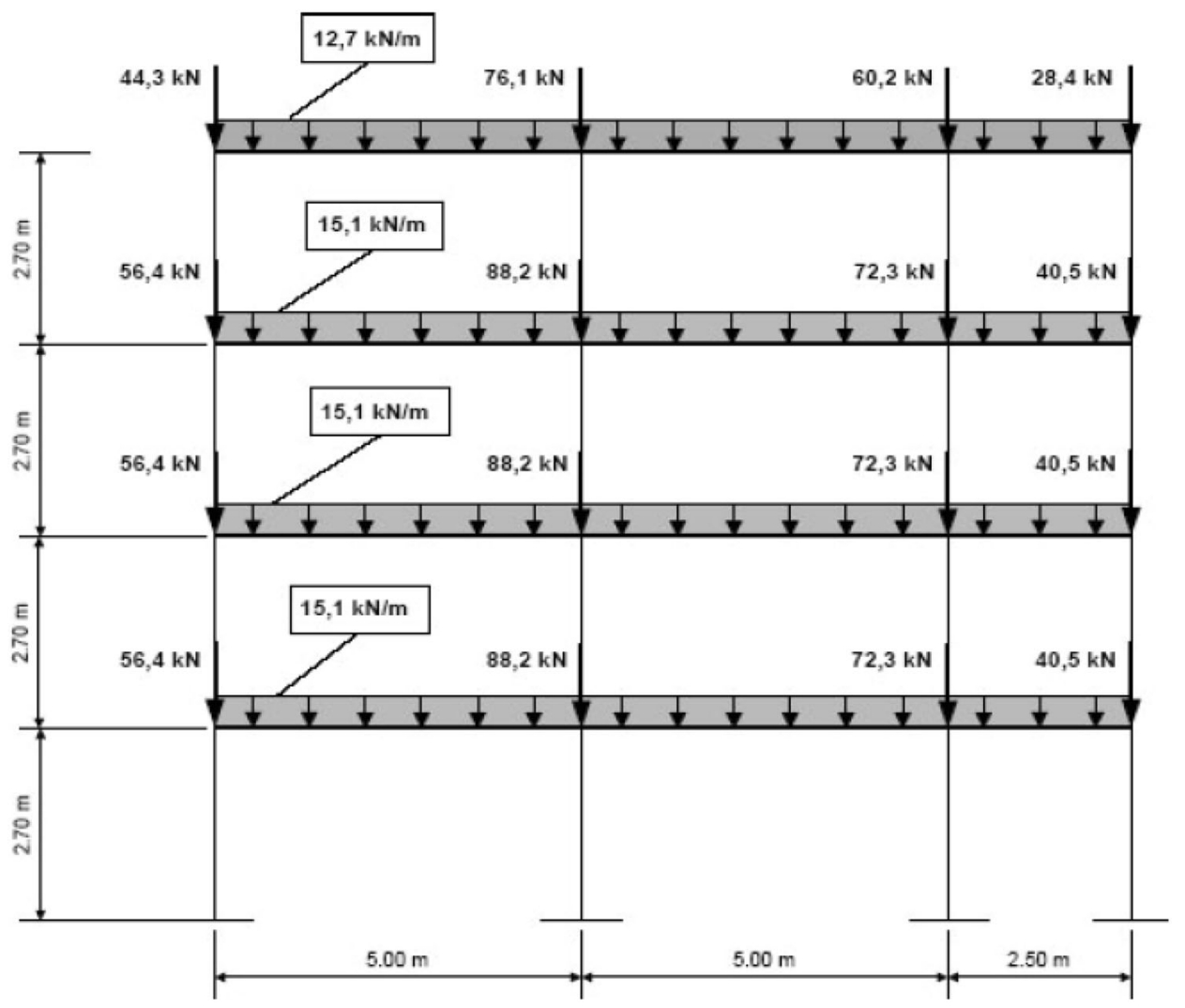

Fig. 8 Scheme of vertical loads for nonlinear analysis, after Carvalho et al. (1999).
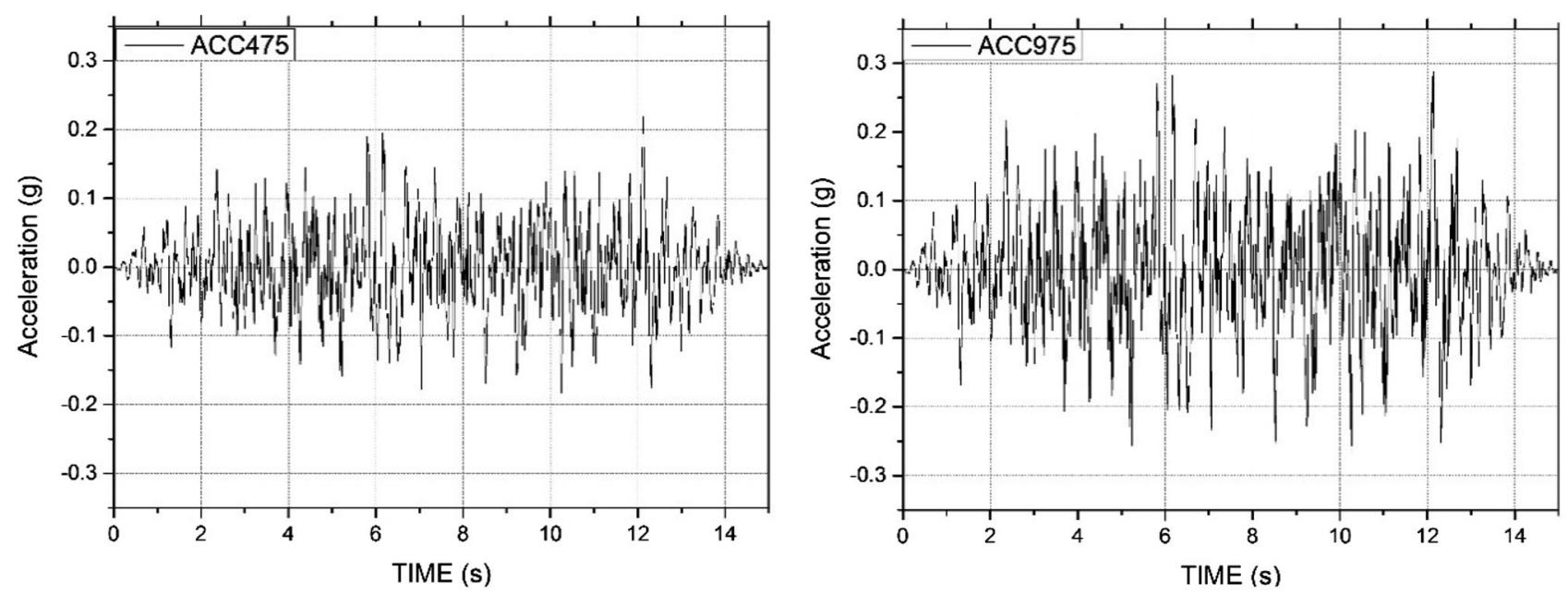

Fig. 9 Acceleration time histories for 475, 975 years return period.

$$
E_{s e c}=\frac{f_{c c}^{\prime}}{\varepsilon_{c c}}
$$

The characteristic parameters are listed below: $f_{c}=16300 \mathrm{kPa}, \quad f_{t}=1900 \mathrm{kPa}, \quad \varepsilon_{c}=0.002 \mathrm{~m} / \mathrm{m}$, $E_{c}=18975 \mathrm{MPa}$.

\subsubsection{Steel Model}

The cyclic behavior of the steel bars is simulated using the classical Menegotto and Pinto (1973) model with kinematic hardening (Fig. 12) and possibility to take into account buckling by introducing a negative modulus slope in compression depending on the transverse steel reinforcement spacing. The monotonic behavior is defined through the initial Young's modulus $\left(E_{s}\right)$, the plastic threshold $\left(\varepsilon_{s y}, \sigma_{s y}\right)$, the ultimate strength and strain $\left(\varepsilon_{u}, \sigma_{u}\right)$ and the yielding slope $\left(E_{h}\right)$. The unloading and reloading process, is guided by analytic relations (Eqs. 26-29) corresponding to a set of curves ranging between the elastic and the yielding asymptotes. 


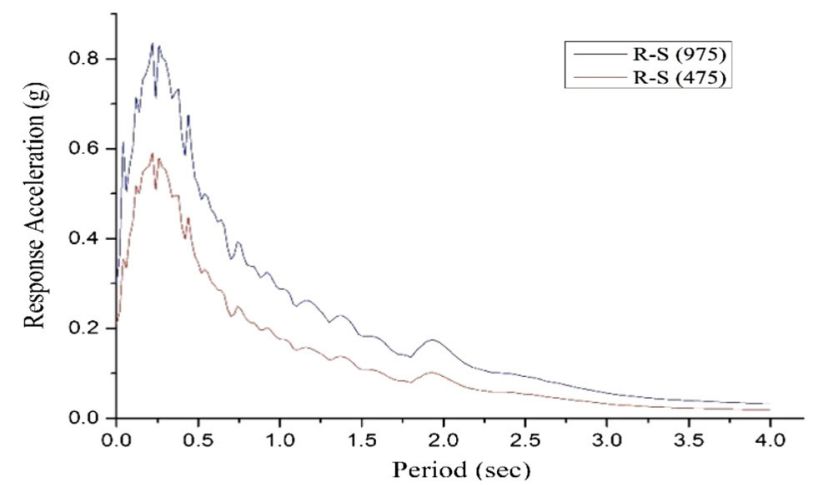

Fig. 10 Response spectra of the accelerograms ACC475 and ACC 975.

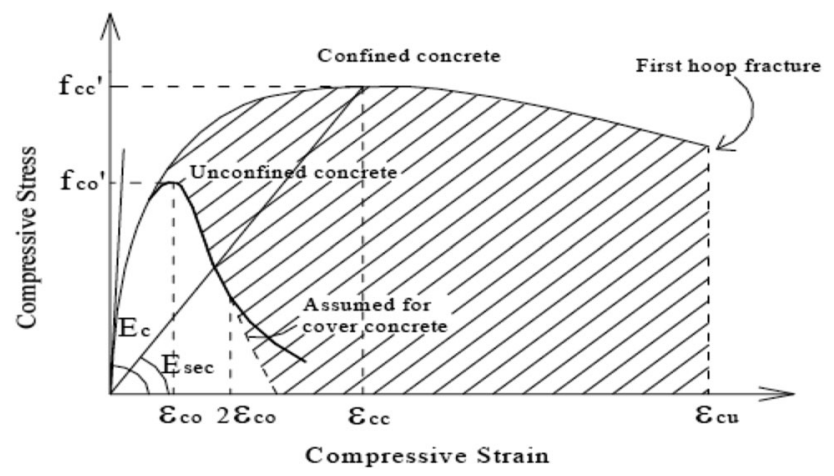

Fig. 11 Mander et al. (1988) model for monotonic response of confined and unconfined concrete.

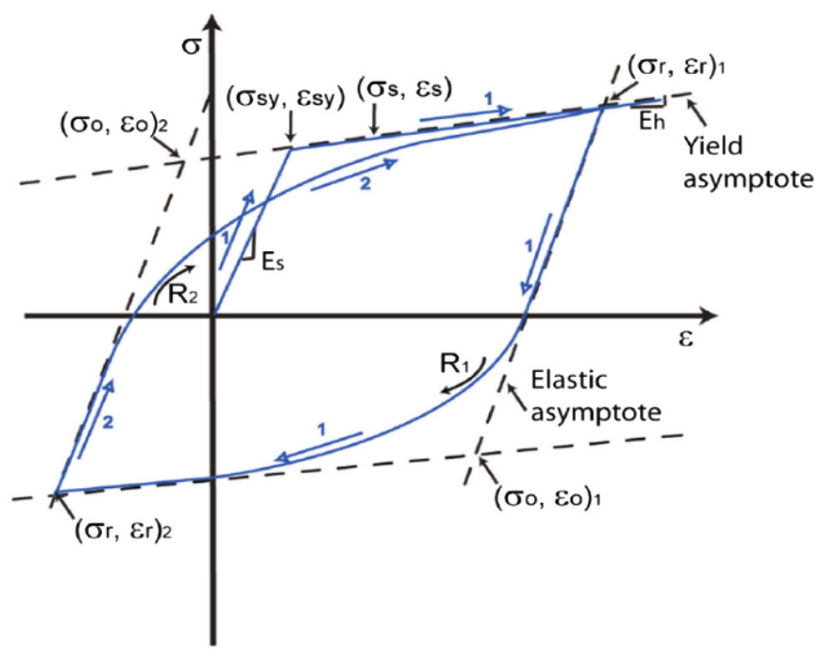

Fig. 12 Menegotto-Pinto steel model.

$$
\sigma^{*}=b \varepsilon^{*}+\left[\frac{1-b}{\left(1+\left(\varepsilon^{*}\right)^{R}\right)^{1 / R}}\right]
$$

where:

$$
\sigma^{*}=\frac{\sigma_{s}-\sigma_{r}}{\sigma_{0}+\sigma_{r}}
$$

$$
\begin{aligned}
& \varepsilon^{*}=\frac{\varepsilon_{s}-\varepsilon_{r}}{\varepsilon_{0}+\varepsilon_{r}} \\
& R=R_{0}-\frac{A_{i} \xi}{A_{j}+\xi}
\end{aligned}
$$

Tension: $i=1$ and $j=2$; Compression: $i=3$ and $j=4$. $\left(\sigma_{s}, \varepsilon_{s}\right)$ is the studied point; $\left(\sigma_{o}, \varepsilon_{o}\right)$ is the crossing point of the elastic and yielding slopes; $\left(\sigma_{r}, \varepsilon_{r}\right)$ are the coordinates of the previous point of load reversion; $\mathrm{b}$ is the $E_{h} / E_{s}$ ratio; $\mathrm{R}$ is a shape parameter; $\xi$ is the ratio between the maximum reached strain during loading; $\varepsilon_{o}, R_{o}, A i$ and $A_{j}$ are material constants that can be obtained from experimental results. A detailed description of the model is presented in Menegotto and Pinto (1928).

The Menegotto-Pinto steel model is employed for defining the steel material with the following properties:

$E_{s}=2.00 \mathrm{E}+008 \mathrm{kPa}, f_{y}=343000 \mathrm{kPa}, \mu=0.0024$.

The materials considered at the design phase were a low strength concrete class $\mathrm{C} 16 / 20(\mathrm{CEN}, 1991)$ and smooth reinforcement steel class Fe B22 k (Italian standards). The latter refers to smooth bars with a yield stress of $235 \mathrm{MPa}$ and ultimate strength of $365 \mathrm{MPa}$.

\section{Results and Discussion}

\subsection{Displacement}

In order to evaluate the level of accuracy obtained with the different modeling strategies, the first step is to evaluate the global response of the structure under seismic action. The roof time-displacement trends for the studied frame are depicted in Figs. 13 to 18 respectively, obtained by using inelastic force-based elements (IFBE) and inelastic displacement-based elements (IDBE) with distributed and concentrated plasticity, taking into account the subdivision of elements.

Figure 13 shows the top displacement depending on the number of integration points for force-based elements. The results found indicate that in the first few seconds (less than $5 \mathrm{~s}$ ), the influence of the number of integration points on the seismic response is negligible, but between 5 and $13 \mathrm{~s}$ for the BF475 earthquake and 5 and $10 \mathrm{~s}$ for the BF975 earthquake, the numerical results for the three points integration scheme are different from the experimental ones. The results given by the four and five integration points schemes are in good agreement with the experimental results.

Figure 14 shows the effect of the discretization of the force-based elements on the global behavior of a structure under seismic loading. The influence of the discretization is negligible in all analyses.

Figure 15 shows a comparison between experimental and numerical results obtained by using different equations to evaluate the length of the plastic hinge for the force-based elements. The displacements obtained by Eq. (15) in both cases are larger than those obtained from the experimental test, moreover, Eqs. (13), (14) and (16) give almost identical results in the first case (BF475 earthquake), but in the 2nd 


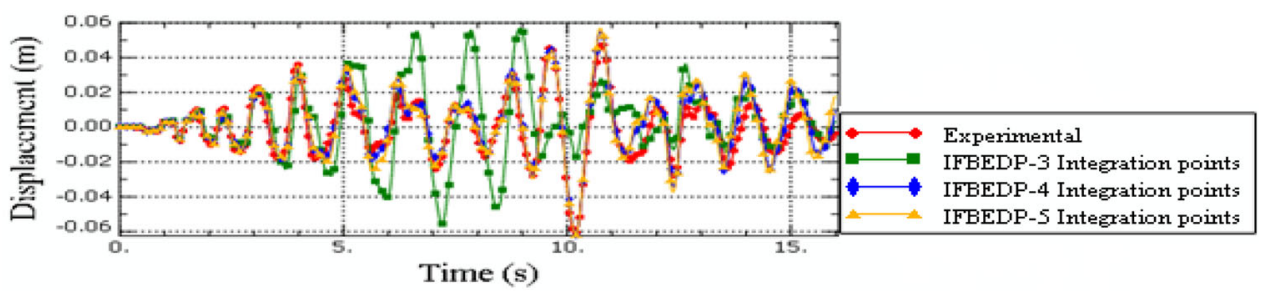

(a)

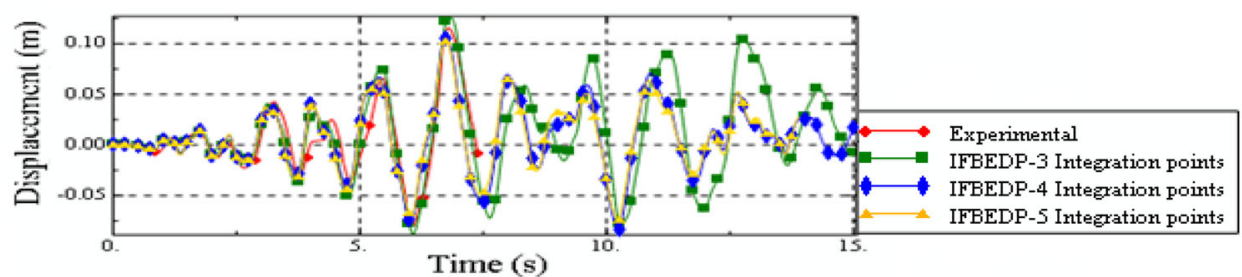

(b)

Fig. 13 Effect of varying the number of integration points on the computed global response in FB formulation for the: a BF475 and b BF975 tests.

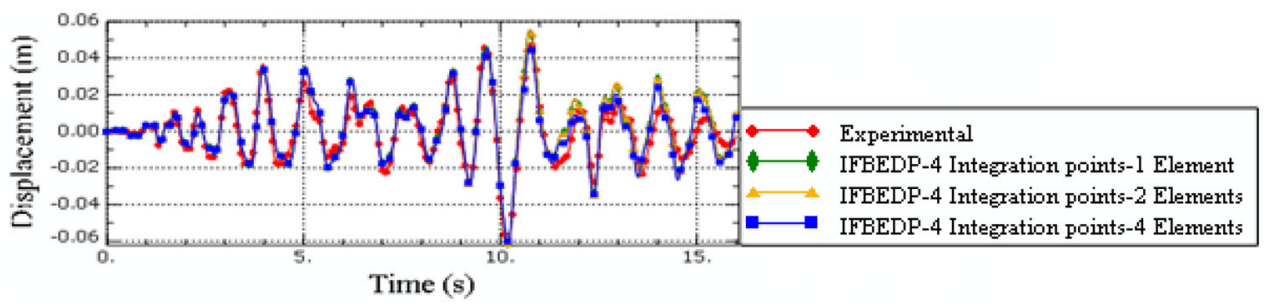

(a)

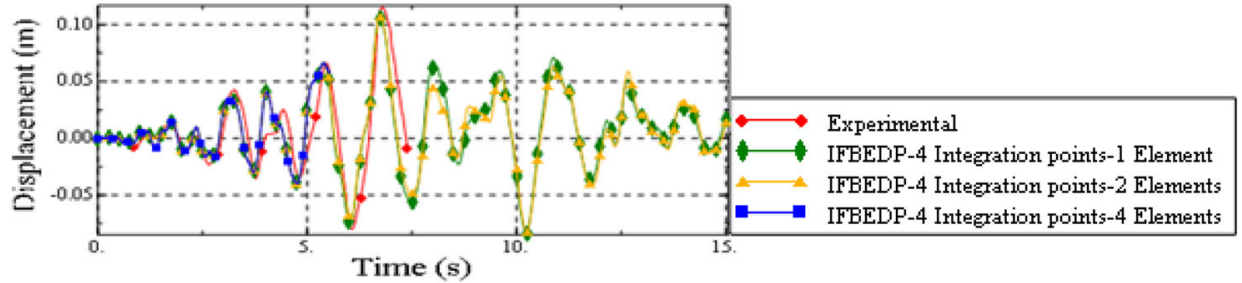

(b)

Fig. 14 Effect of the different number elements with four integration points in FB formulation of the: a BF475 and b BF975 tests.

case (BF975 earthquake), Eq. (16) gives different results compared to experimental Results. These differences between the analytical and experimental results can be attributed to the assumed value of the plastic hinge length and to the frequency content of the earthquake.

The results of a nonlinear analysis using displacementbased elements with varying number of discretization of the elements is shown in Fig. 16. The results show clearly that the number of elements affects the displacement values, and that increasing the number of elements up to 4 elements in the columns and beams results in a good convergence to the experimental results.

In this section, Fig. 17, a discretization of columns and beams at their ends was used in order to capture the nonlinearity of materials (concrete and steel). We note that the discretization in two and four elements gives a good convergence to the experimental results than a single element. It should be noted that for a discretization with 4 elements, the analysis stopped for BF975 earthquake.

Figure 18 show a comparison between the experimental results and the numerical results using displacement-based elements with concentrated plasticity (plastic hinges length is equal to zero at the ends). The results are in good agreement for the first few seconds $(<5 \mathrm{~s})$, but after the fifth second there is a remarkable divergence between the numerical and experimental results.

\subsection{Inter Storey Drift}

The lateral deformability of structural systems is measured through the horizontal drift. In buildings, storey drifts $\Delta$ are the absolute displacements of any floor relative to the base, while inter-storey drifts $\delta$ define the relative lateral 


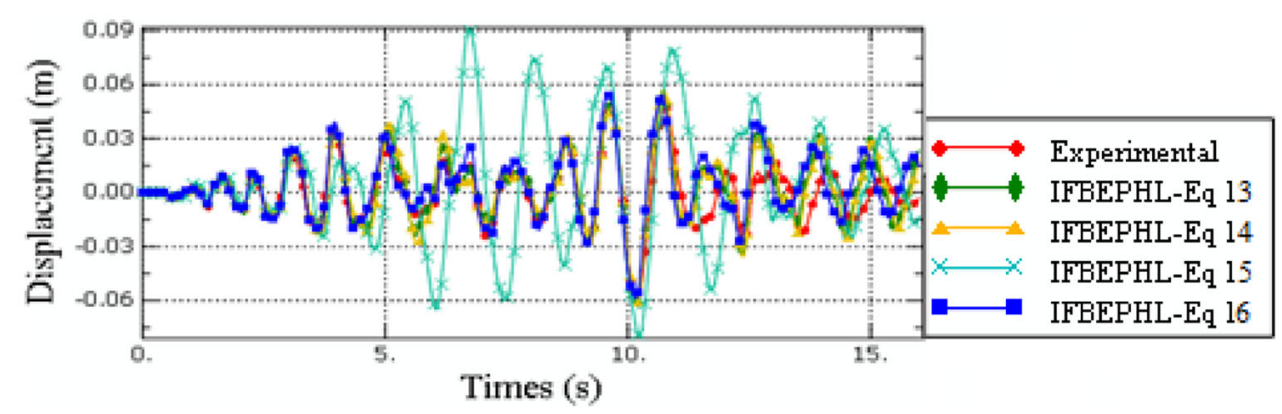

(a)

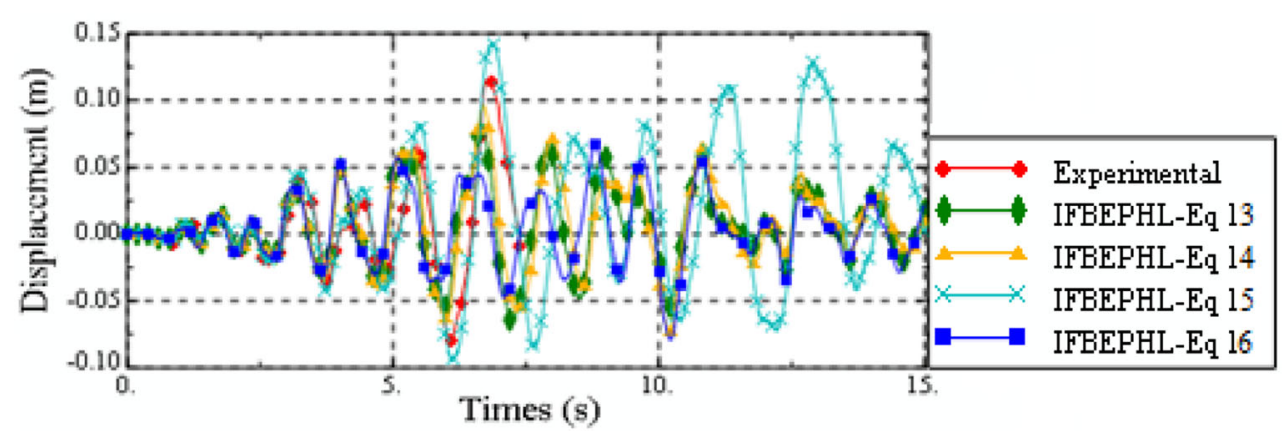

(b)

Fig. 15 Effect of plastic hinge length in FB formulation For the: a BF475 and b BF975 tests.

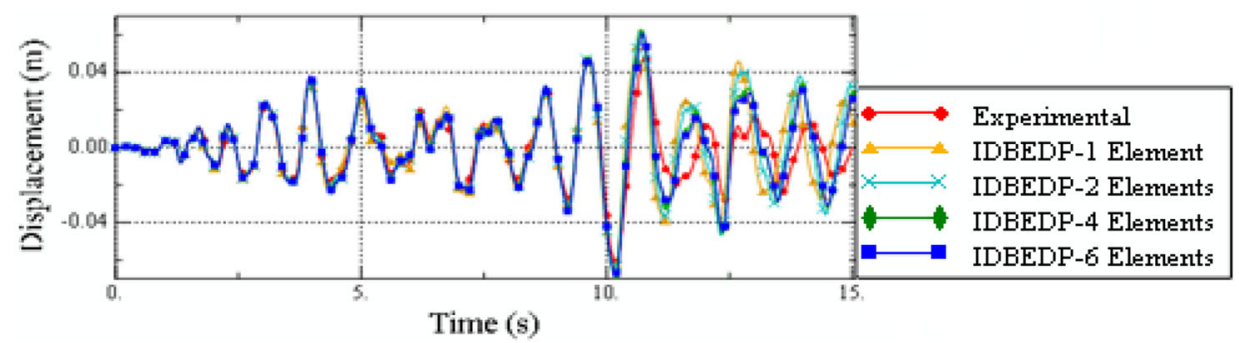

(a)

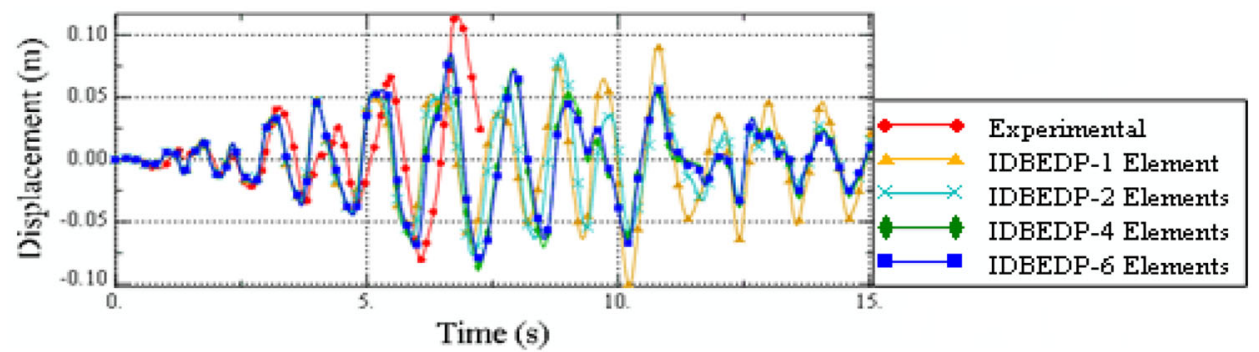

(b)

Fig. 16 Effect of varying the number elements in DB formulation for the: a BF475 and b BF975 tests.

displacements between two consecutive floors. The interstorey drifts are generally expressed as ratios $\delta / h$ of displacement $\delta$ to storey height $h$. Drifts of the roof $\Delta$ normalized by the total height $H$ of the building (roof drifts, $\Delta /$ $H$ ) are also used to quantify the lateral stiffness of structural systems. The roof drift ratio $\Delta / H$ may be considered $\delta / h$ averaged along the height and hence is not suitable for quantifying variations of stiffness in the earthquake-resisting system.
Inter-storey drifts are caused by flexural, shear and axial deformations of structural elements, e.g. beams, columns, walls and connections. Axial deformations due to shortening or elongation of members are generally negligible; flexural and shear deformations are the primary cause of nonstructural damage.

Figure 19 shows a plot of the vertical distribution of the maximum story-drift of the main frame. It is clear that the analytical model is able to predict the soft-storey at the third 


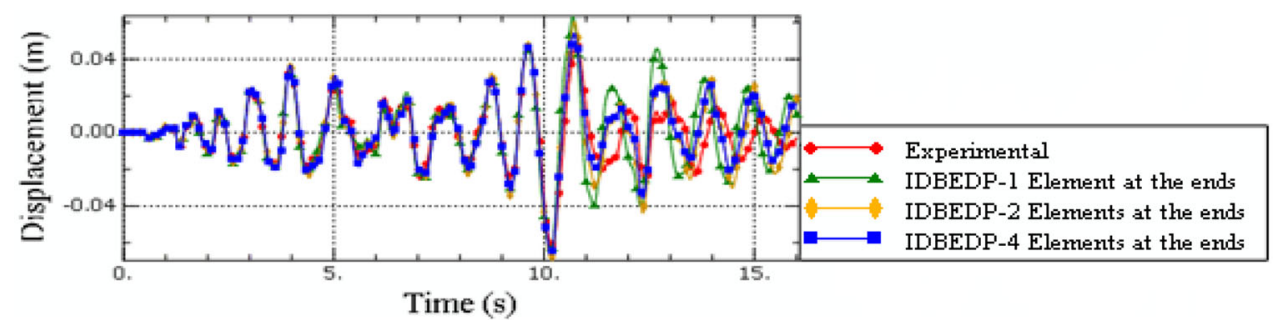

(a)

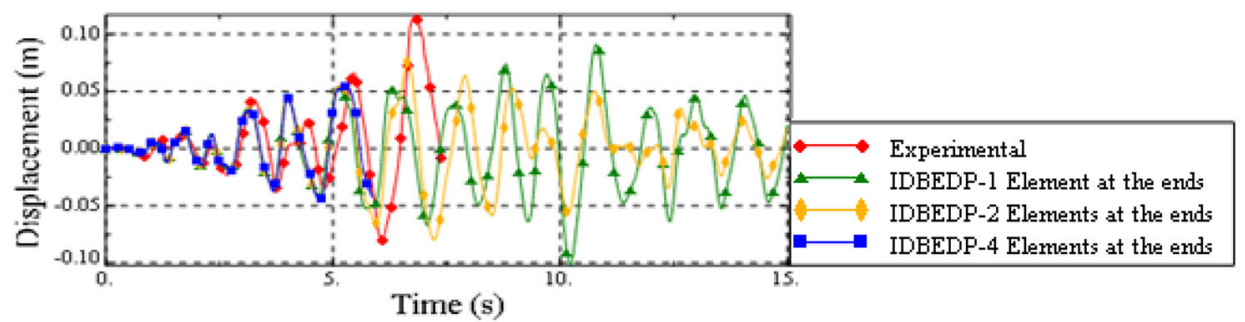

(b)

Fig. 17 Effect of the varying the number elements at the ends in DB formulation for the: a BF475 and b BF975 tests.

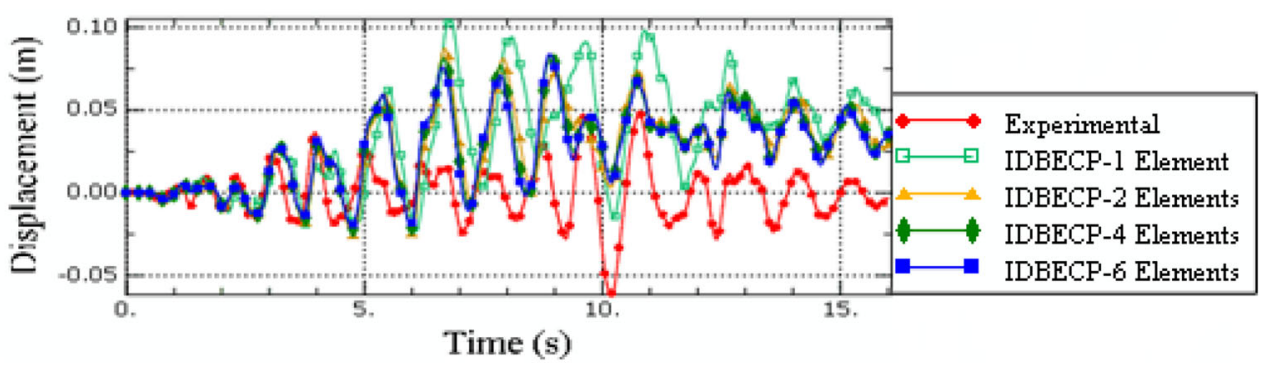

(a)

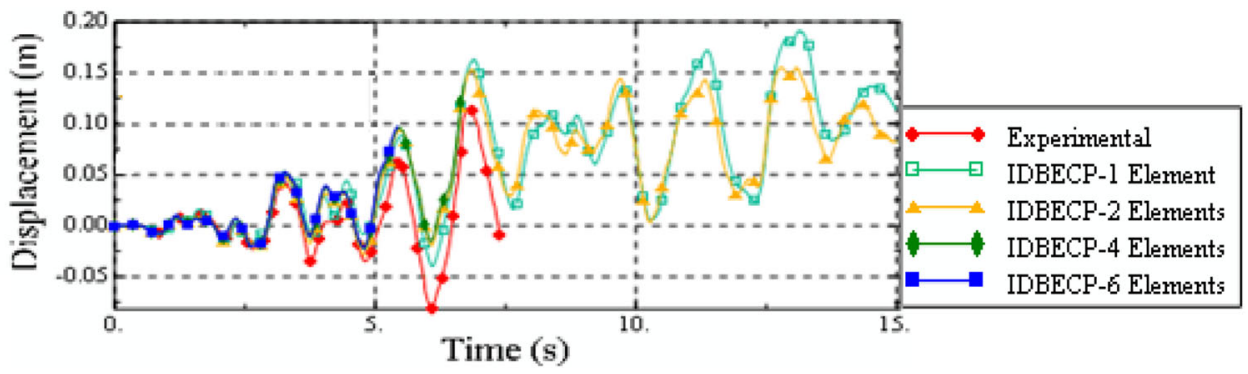

(b)

Fig. 18 Effect of the varying the number elements in displacement-based formulation with concentrated plasticity for the: a BF475 and b BF975 tests.

floor. Further refinement of the analytical model could perhaps produce a closer match between the analytical and experimental drift profiles but this is not within the scope of the present exercise. It suffices that the nonlinear fiber analysis can predict the soft-storey at the third floor and thus this will be the reference to which all other analytical analyses will be compared, as can be observed in these figures, inter-storey drift ratios of regular frames, satisfy the requirements of the LS performance level (limiting drift $2 \%)$.
The comparison between the experimental and the different numerical models for the maximum storey shear is shown in Fig. 20. Storey forces or shears are no longer applied directly to the structure but rather come as a result of structural equilibrium to the applied displacement pattern, thus allowing for the reproduction of reversal of storey shear distributions. The shear distributions are automatically derived to attain structural equilibrium with the imposed storey drifts, rather than being a result of the loads directly applied to the structure. We can see in the tow earthquakes 


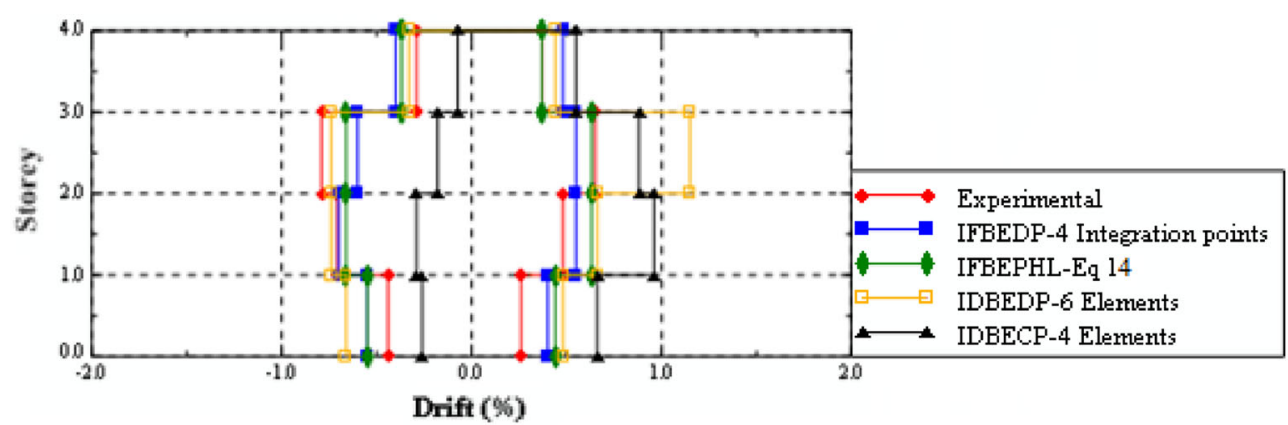

(a)

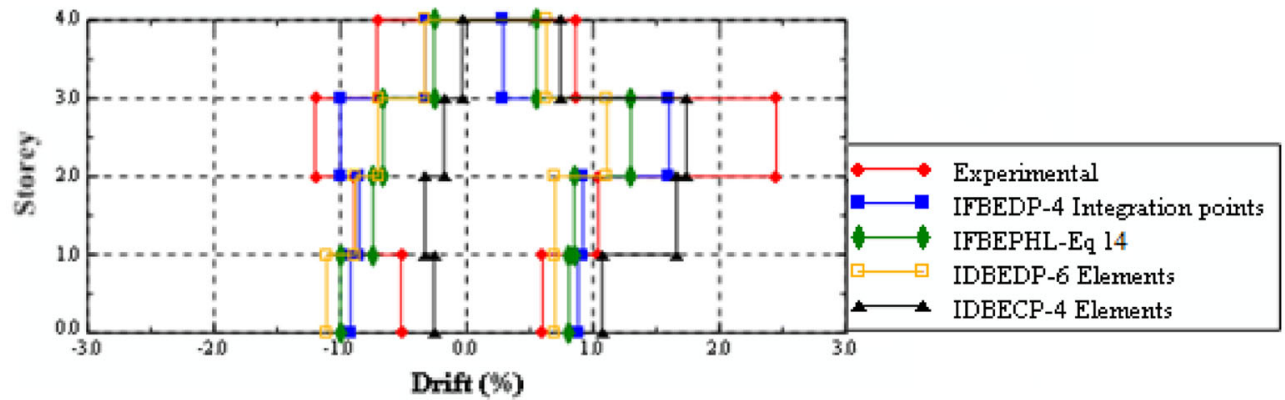

(b)

Fig. 19 Maximum interstorey drift profiles for a four-storey using force and displacement-based with dynamic analysis of the: a BF475 and b BF975 tests.

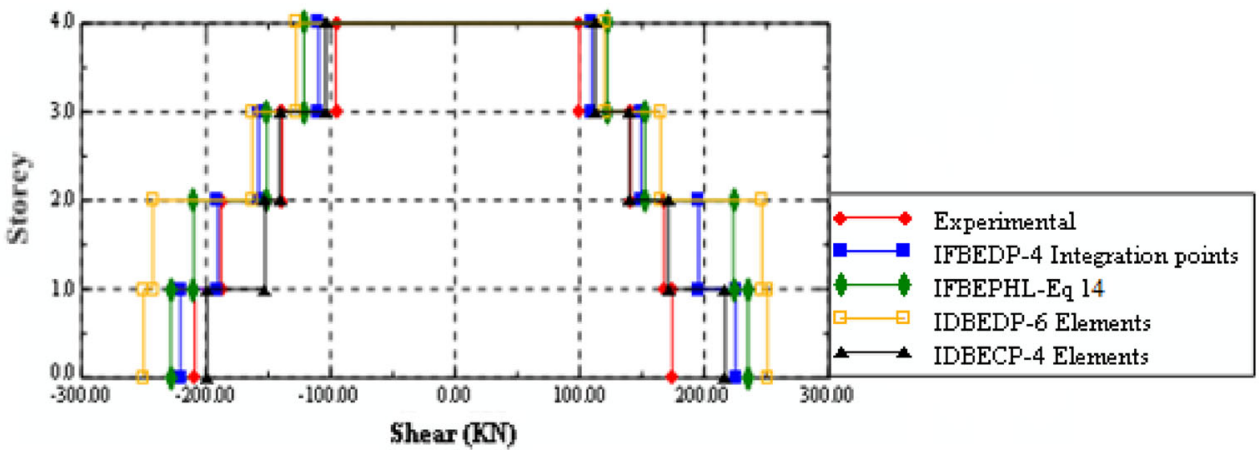

(a)

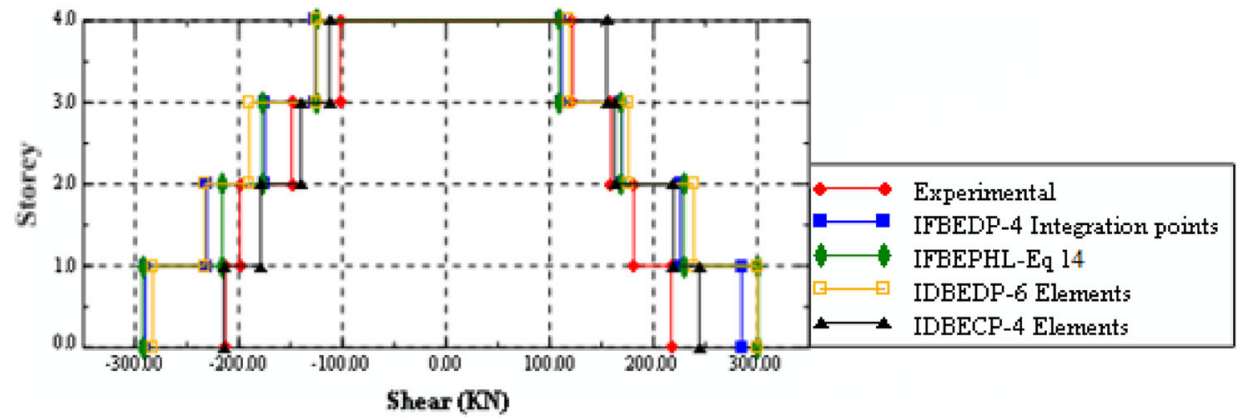

(b)

Fig. 20 Maximum storey shear profiles for a four-storey using force and displacement-based for the: a BF475 and b BF975 tests.

(BF475 and BF975), the models give good convergences compared to the experimental results and these models can predict the response of the structure especially for the IDBECP-4 Elements model.

\subsection{Energy Dissipation for Various Models}

Based on principles of earthquake engineering, for proper seismic behavior of structure, the input energy to the structure due to earthquakes need to be absorbed and/or 


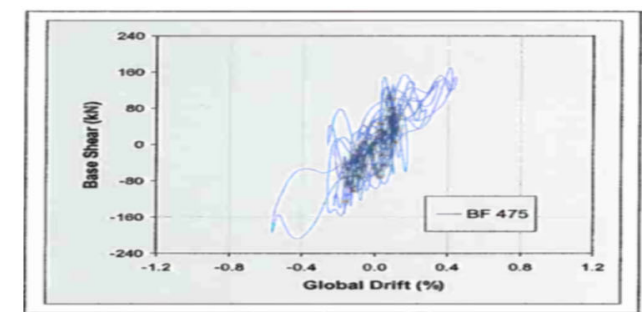

Experimental (a)
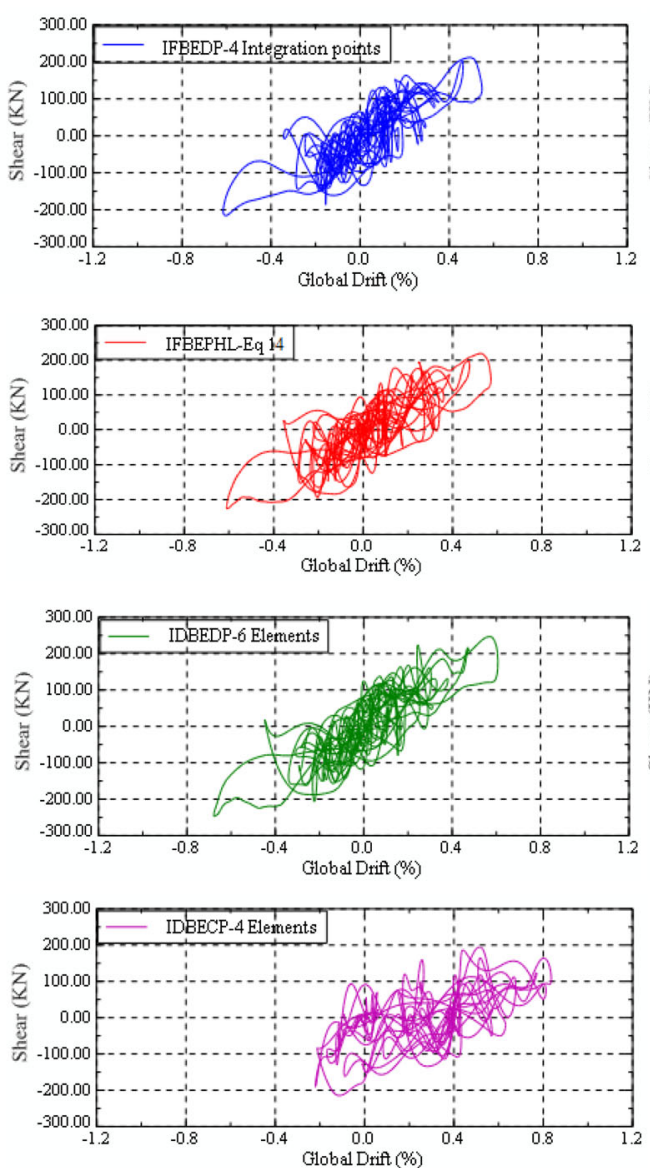

(a)

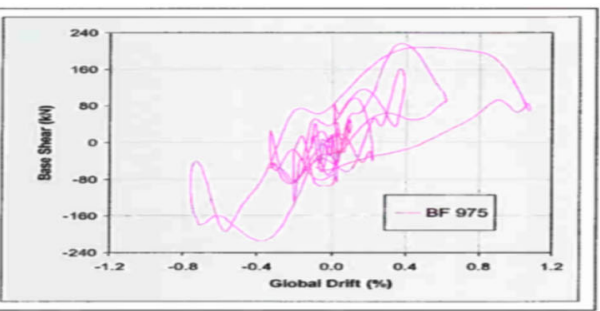

Experimental (b)
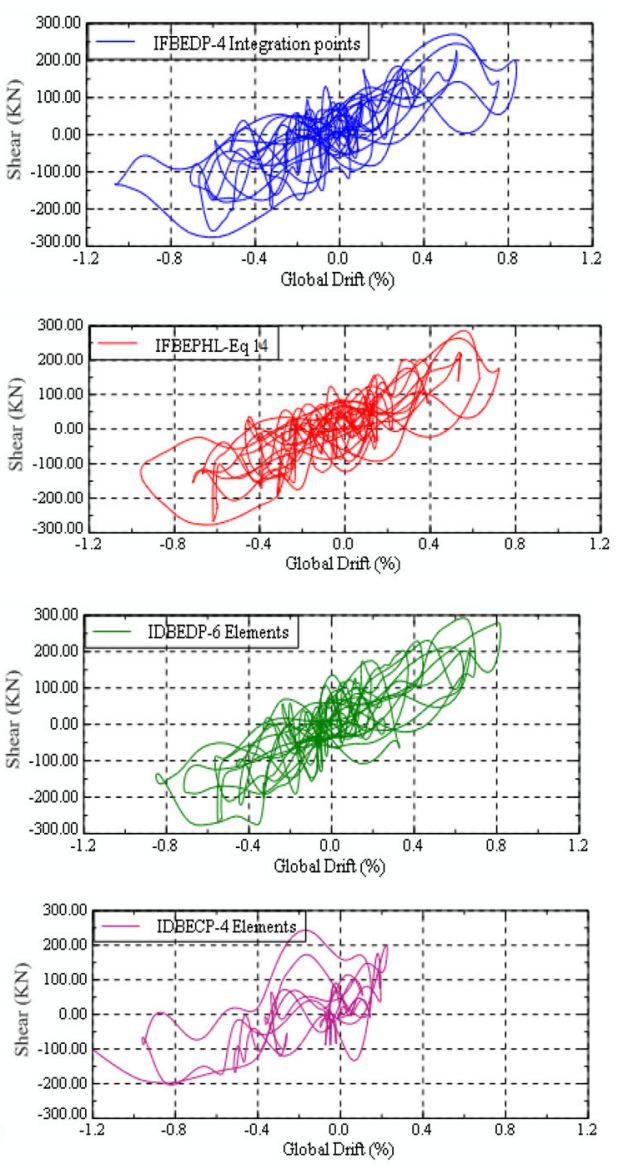

(b)

Fig. 21 Base-shear versus top-displacement curves for the: a BF475 and b BF975 tests.

dissipated, depending on the expected performance of the structure. Energy absorption and dissipation in structures is usually due to two main sources, the inherent damping of the structural system, and formation of plastic hinges in structural components and nonlinearity.

The global base shear force versus roof lateral displacement hysteretic response is plotted in Fig. 21 for the BF475 and BF975 tests. For the BF475 test, the response remained practically within the elastic range as illustrated in Fig. 21a. The BF475 test deformed the building to a maximum roof displacement equal to $0.6 \mathrm{~m}$, while the maximum base shear force was $180 \mathrm{kN}$. Figure $21 \mathrm{~b}$ shows the plot of the base shear versus roof displacement hysteretic curves for the BF975 test. At this higher intensity earthquake, some nonlinear effects with noticeably wider force-displacement loops characterized the response of this system. The peak roof displacement and maximum base shear force measured in this test were $0.1 \mathrm{~m}$ and $200 \mathrm{kN}$. The IFBEDP-4 Integration points model showed the best correlation with the experimental results.

\subsection{Damage Pattern \\ 7.4.1 Experimental Damage Results}

The RC frame behaviour was classified as satisfactory for the seismic action characterized by the accelerogram BF475 , not showing significant global damage, but only small local damage. With the accelerogram BF-975 and only for less than half of test time, the damage observed was stronger, mainly on the third storey wide column where some extensive cracks appear (Fig. 22). The test was stopped at half of the time in order to prevent irreparable damage and to allow the use of the retrofit solutions. 


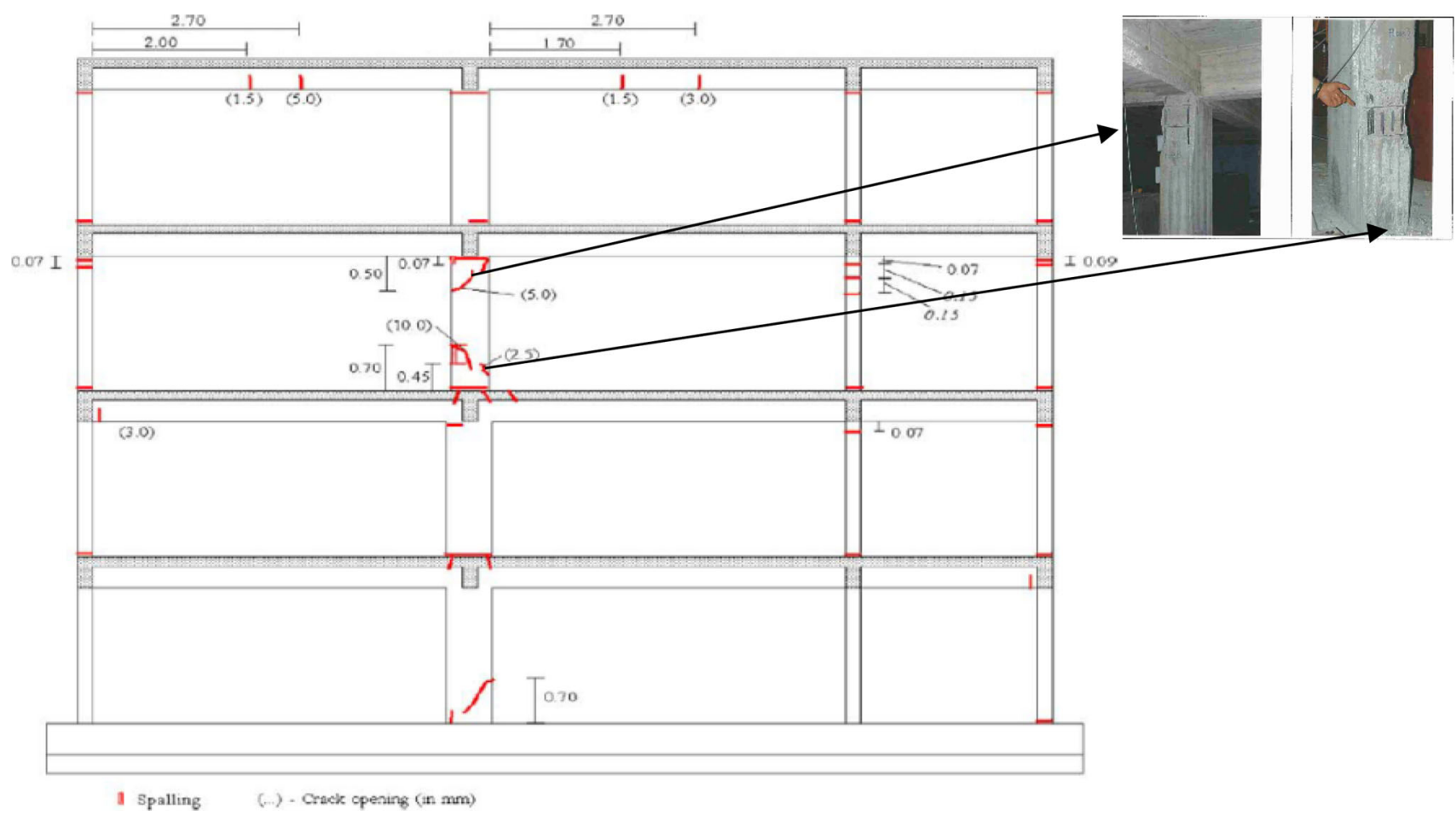

Fig. 22 After BF PsD earthquake testes: damage observed on the 3rd storey column.

Figure 23 shows different levels of damage within the numerical models, the damage in frame structures using the IDBEDP and IDBECP elements are not identical to the damage observed in the experimental test for both seismic loadings. The analysis with IFBEPHL and IFBEDP elements shows that these elements can capture the damage in the soft storey on the third storey column, where the limit states LS and CP are apparent, this indicates that the models with the last elements are good for predicting damage in nonlinear analysis of RC structures. The damage of member element of structure under bar buckling effect is not apparent in this study because the plastic rotation values are greater than the collapse values of elements since the structure is not excited to high intensity loading in this test.

\section{Conclusion}

This study is concerned with the evaluation of the accuracy and efficiency of commonly available numerical models for RC frame elements. Four representative numerical models, reproducing an experimental test widely referred in recent literature, have been used. The consequences of different modeling assumptions, such as element formulation, mesh discretization, number of integration points, were investigated under different earthquakes (BF475, BF975). The main findings are:

- The two major types of distributed inelasticity frame elements, displacement-based (DB) and force-based (FB), rely on completely different finite element assumptions and are thus expected to yield rather different results under non-linear analyses.

- Unlike the DB approach, the FB relies on the assumption of force shape functions along the element, which always verify exact equilibrium independently of the sectional constitutive relations (linear or non-linear). This implies a somehow more "complicated" state determination procedure, but theoretically no meshing is required.

- A Gauss-Lobatto integration scheme should be used for FB elements. Although a lower bound of 4 integration points element is required in order to provide a reliable result, a choice of a larger number of, for instance, five integration points can also be justifiable in order to obtain a completely stabilized prediction of the response.

- Regardless of good prediction of force-based beamcolumn element peak forces, the lumped plasticity with plastic hinge length for Eqs. (14) and (16) exhibit better performance on predicting the seismic response of RC frame elements, and Eq. (19) could be influenced by the frequency content of the earthquake, but Eq. (17) does not give good results for the two earthquakes (BF475 and BF975).

- DB formulations show a quickly converging response when the number of elements increases. However, a minimum number of four elements is required to attain an acceptable degree of accuracy in modeling the inelastic response.

- The concentrated plasticity models have the disadvantage of separating the strength-moment interaction and the axial stiffness interaction of the element's behavior, and the need to undertake a moment-curvature analysis 


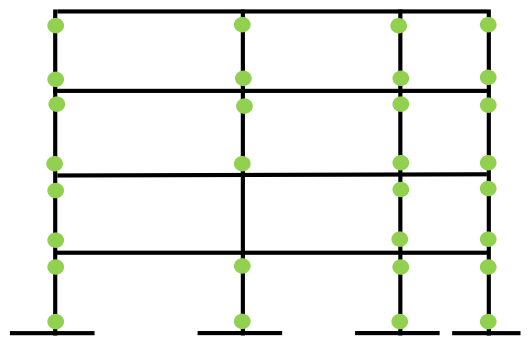

(a)

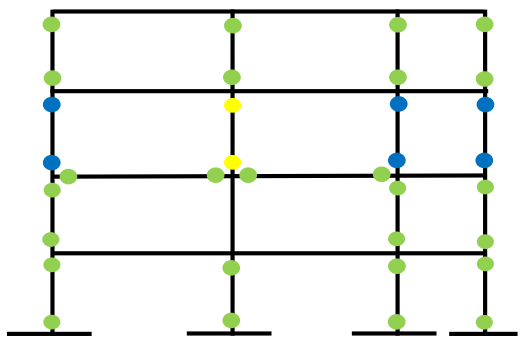

(b)

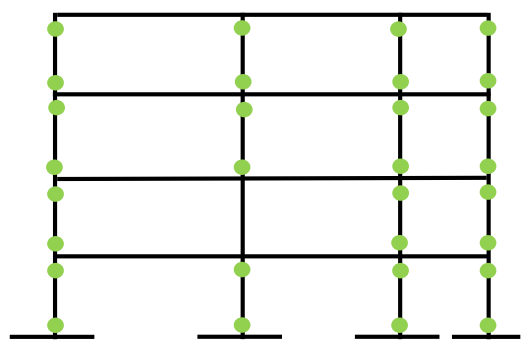

(a)

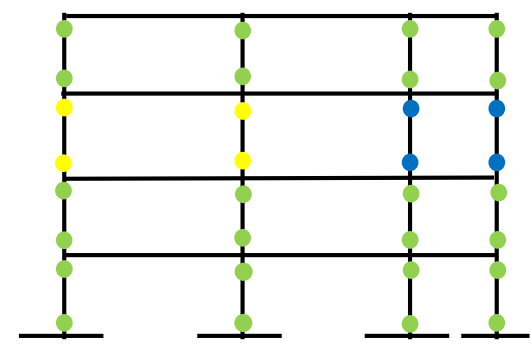

(b)

IFBEPHL - Eq 14

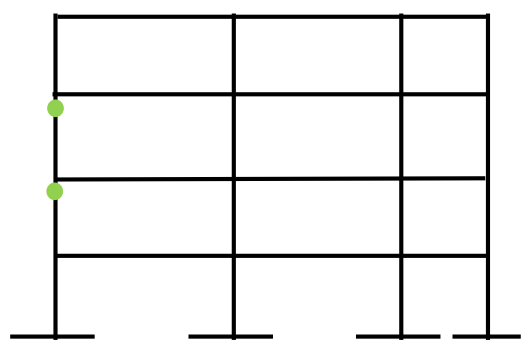

(a)

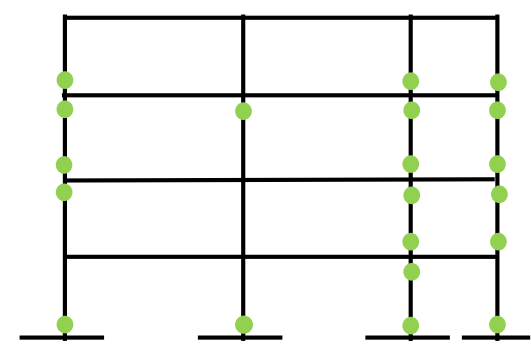

(b)

IDBEDP - 6 Elements

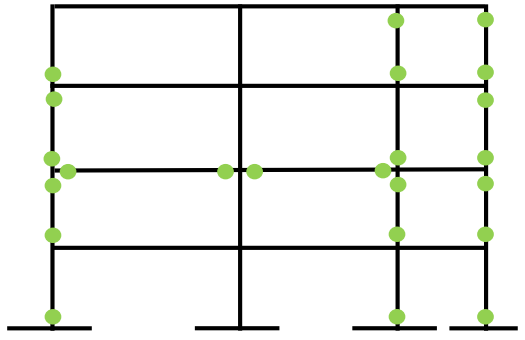

(a)

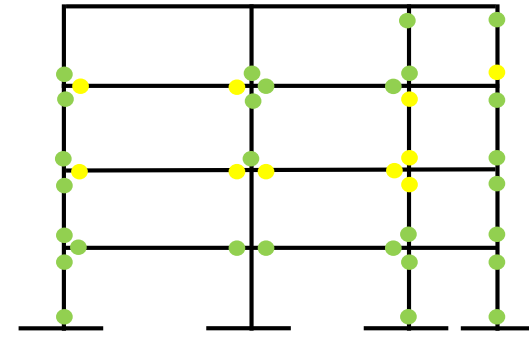

(b)

IDBECP - 4 Elements

IO: immediate occupancy, LS: life safety, $\bigcirc \mathrm{CP}$ : collapse prevention, $\bigcirc \mathrm{BB}$ : Bar buckling.

Fig. 23 Typical damage pattern and plastic hings formation for the seismic tests: a BF475 and b BF975 tests

to determine the elastic and post-elastic stiffness, and the nonlinear interaction axial force-moment envelope.

- The frequency content of the earthquake is seen to influence notably the nonlinearity response.
- The limit states based on the plastic rotation in model with FB formulations are good for prediction the damage in nonlinear analysis of RC structures.

- A high intensity seismic loading is required for a damage to appear under the buckling of a bar. 


\section{Open Access}

This article is distributed under the terms of the Creative Commons Attribution 4.0 International License (http://creativecommons.org/licenses/by/4.0/), which permits unrestricted use, distribution, and reproduction in any medium, provided you give appropriate credit to the original author(s) and the source, provide a link to the Creative Commons license, and indicate if changes were made.

\section{References}

Almeida, J. P., Das, S., \& Pinho, R. (2012). RC frame analysis with a new damage-following model. World Conference on Earthquake Engineering (15WCEE), Lisboa, Portugal, 2012.

Berry, M. P., \& Eberhard, M. O. (2005). Practical performance model for bar buckling. Journal of Structural Engineering, 131, 1060-1070.

Berry, M. P., Lehman, D. E., \& Lowes, L. N. (2008). Lumpedplasticity models for performance simulation of bridge columns. ACI Structural Journal, 105, 270-279.

Calabrese, A., Almeida, J. P., \& Pinho, R. (2010). Numerical issues in distributed inelasticity modeling of $\mathrm{RC}$ frame elements for seismic analysis. Journal of Earthquake Engineering, 14(S1), 38-68.

Carvalho, E. C., Coelho, E., \& Campos-Costa, A. (1999). Preparation of the full-scale tests on reinforced concrete frames. Characteristics of the test specimens, materials and testing conditions, ICONS Report, Innovative Seismic Design Concepts for New and Existing Structures, European TMR Network, LNEC.

Coleman, J., \& Spacone, E. (2001). Localization issues in forcebased frame elements. Journal of Structural Engineering, 127, 1257-1265.

Eberhard, M. O. (2000). Consequences of bridge damage on functionality. Proc., PEER Invitational Workshop on Performance-Based Engineering Concepts for Bridges, Palo Alto, Calif.

FEMA-273. (1997). NEHRP guidelines for the seismic rehabilitation of buildings. Washington, DC.

FEMA-356. (1997). Prestandard and commentary for the seismic rehabilitation of buildings. Washington, DC.

Filippou, F. C. \& Fenves, G. L. (2004). Methods of analysis for earthquake-resistant structures. Earthquake engineering: From engineering seismology to performance-based engineering, Bozorgnia Y, Bertero VV. eds. Chap. 6, CRC, Boca Raton, FL.

Giberson, M. F. (1967). The response of nonlinear multi-story structures subjected to earthquake excitation, doctoral Dissertation, California Institute of Technology, Pasadena, CA, pp.232.

Giberson, M. F. (1969). Two nonlinear beams with definition of ductility. Journal of the Structural Division, ASCE, 95(2), 137-157.

Hashemi, S. S., \& Vaghefi, M. (2012). Cyclic analysis of RC frames with respect to employing different methods in the fiber model for consideration of bond-slip effect. Turkish $J$. Eng. Env. Sci, 36, 1-18.

Huang, X., \& Kwon, O. (2015). Numerical models of RC elements and their impacts on seismic performance assessment. Earthquake Engineering and Structural Dynamics, 44, 283-298.

Inel, M., \& Ozmen, H. B. (2006). Effects of plastic hinge properties in nonlinear analysis of reinforced concrete buildings. Engineering Structures, 28, 1494-1502.

Jeong, S. H., \& Elnashai, A. S. (2005). Analytical assessment of an irregular RC frame for full scale 3D pseudo-dynamic testing Part I: analytical model verification. Journal of Earthquake Engineering, 9, 95-128.

Ladjinovic, D. J., Raseta, A., Radujkovic, A., Folic, R., \& Prokic, A. (2012). Comparison of structural models for seismic analysis of multi-storey frame buildings. World Conference on Earthquake Engineering (15WCEE), Lisbon, Portugal, 2012.

Lehman, D. E., Gookin, S. E., Nacamuli, A. M., \& Moehle, J. P. (2001). Repair of earthquake-damaged bridge columns. ACI Structural Journal, 98(2), 233-242.

Limkatanyu, S., \& Spacone, E. (2002). Reinforced concrete frame element with bond interfaces. I: displacement-based, force-based, and mixed formulations. Journal of Structural Engineering, 128, 346-355.

Mander, J., Priestley, M., \& Park, R. (1988). Theoretical stressstrain model for confined concrete. Journal of Structural Engineering, 114, 1804-1826.

Mazza, F., \& Mazza, M. (2010). Nonlinear analysis of spatial framed structures by a lumped plasticity model based on the Haar-Kàrmàn principle. Computational Mechanics, 45, 647-664.

Menegotto, M., \& Pinto, P. E. (1973). Method of analysis for cyclically loaded reinforced concrete plane frames including changes in geometry and non-elastic behavior of elements under combined normal force and bending moment (pp. 15-22). Lisbon, Portugal: IASBE Proceedings.

Panagiotakos, T. B., \& Fardis, M. N. (2001). Deformations of reinforced concrete members at yielding and ultimate. $A C I$ Structural Journal, 98, 135-148.

Park, R., \& Paulay, T. (1975). Reinforced concrete structures. NY: Wiley.

Paulay, T., \& Priestley, M. (1992). Seismic design of reinforced concrete and masonry buildings (p. 767). NY: John Wiley and Sons.

Pinto, A. V. G., Verzeletti, G., Molina, J., Varum, H., Pinho, R., \& Coelho, E. (2002). Pseudo-dynamic tests on non-seismic resisting RC frames (bare and selective retrofit frames). European Laboratory for Structural Assessment (ELSA), Research Report EUR20244 EN, Joint Research Centre, Ispra, Italy.

Popovics, S. (1973). A numerical approach to the complete stress-strain curve of concrete. Cement and Concrete Research, 3, 583-599.

Priestley, M. J. N., \& Park, R. (1987). Strength and ductility of concrete bridge columns under seismic loading. $A C I$ Structural Journal, 84(1), 61-76. 
Priestley, M. J. N., Verma, R., \& Xiao, Y. (1994). Seismic shear strength of reinforced concrete columns. Journal of Structural Engineering, 120(8), 2310-2329.

Ramin, K., \& Fereidoonfar, M. (2015). Finite element modeling and nonlinear analysis for seismic assessment of off-diagonal steel braced RC frame. International Journal of Concrete Structures and Materials, 9(1), 89-118.

Richart, F. E., Brandtzæg, A., \& Brown, R. L. (1928). A study of the failure of concrete under combined compressive stresses. University of Illinois Bulletin, 26(12).

Rodrigues, H., Varum, H., Arêde, A., \& Costa, A. (2012). Comparative efficiency analysis of different nonlinear modelling strategies to simulate the biaxial response of RC columns. Earthquake Engineering and Engineering Vibration, 11, 553-566.

Rodriguez, M. E., Botero, J. C., \& Villa, J. (1999). Cyclic stress-strain behavior of reinforcing steel including effect of buckling. Journal of Structural Engineering, 125, 605-612.
Roh, H., Reinhorn, A. M., \& Lee, J. S. (2012). Power spread plasticity model for inelastic analysis of reinforced concrete structures. Engineering Structures, 39, 148-161.

Scott, M. H. \& Fenves, G. L. (2006). Plastic hinge integration methods for force-based beam-column elements. Journal of Structural Engineering ASCE, 132, 244-252.

Scott, M. H., Franchin, P., Fenves, G. L., \& Filippou, F. C. (2004). Response sensitivity for nonlinear beam-column elements. Journal of Structural Engineering ASCE, 130, 1281-1288.

Scott, B. D., Park, R., \& Priestley, M. J. N. (1982). Stress-strain behavior of concrete confined by overlapping hoops at low and high strain rates. ACI Journal, 79, 13-27.

SeismoSoft, SeismoStruct v7. (2015). A computer program for static and dynamic nonlinear analysis of framed structures, available from URL: http//www.seismosoft.com. 